\title{
Multi-scale variation in salinity: a driver of population size and structure in the muricid gastropod Nucella lamellosa
}

\author{
Garth A. Covernton ${ }^{1, *}$, Christopher D. G. Harley ${ }^{2}$ \\ ${ }^{1}$ Department of Biology, University of Victoria, Victoria, BC V8P 5C2, Canada \\ ${ }^{2}$ Department of Zoology and Institute for the Oceans and Fisheries, University of British Columbia, \\ Vancouver, BC V6T 1Z4, Canada
}

\begin{abstract}
The abiotic environment varies continuously at a variety of temporal scales. While this variation is known to be ecologically important, multiple scales of variability are rarely explicitly considered in ecological studies. Here, we combine field observations and laboratory experiments to determine the individual and population level effects of short-term (tidal) and longer-term (seasonal and interannual) salinity variation on the dogwhelk Nucella lamellosa in the Strait of Georgia, British Columbia, Canada. The Fraser River heavily influences surface salinity in the Strait of Georgia, which varies with season, depth, and distance to the river mouth. At low salinity sites, $N$. lamellosa population size decreased following high outflow years, with fewer juveniles present, as opposed to high salinity sites, which had higher population densities in all years. Sustained salinity exposure in the laboratory caused developmental delay of encapsulated embryos and complete mortality at 9 and $12 \mathrm{psu}$. Juvenile dogwhelks ( $<30 \mathrm{~mm}$ shell length) and those from a high salinity site experienced higher mortality in low salinity conditions than larger individuals and those from a low salinity site. The inclusion of a $3 \mathrm{~h}$ daily exposure to $20 \mathrm{psu}$, simulating high tides in a stratified water column, enabled $N$. lamellosa to survive otherwise low salinity conditions for considerably longer. Overall, our results suggest that seasonal and interannual variation in salinity have a profound influence on $N$. lamellosa populations and that shorterscale fluctuations can moderate these seasonal and interannual effects. It is likely that similar multi-scale environmental effects will determine survival and population dynamics in many species.
\end{abstract}

KEY WORDS: Abiotic factors - Gastropod - Nucella Population structure $\cdot$ Salinity tolerance

${ }^{*}$ Corresponding author: gcov@uvic.ca

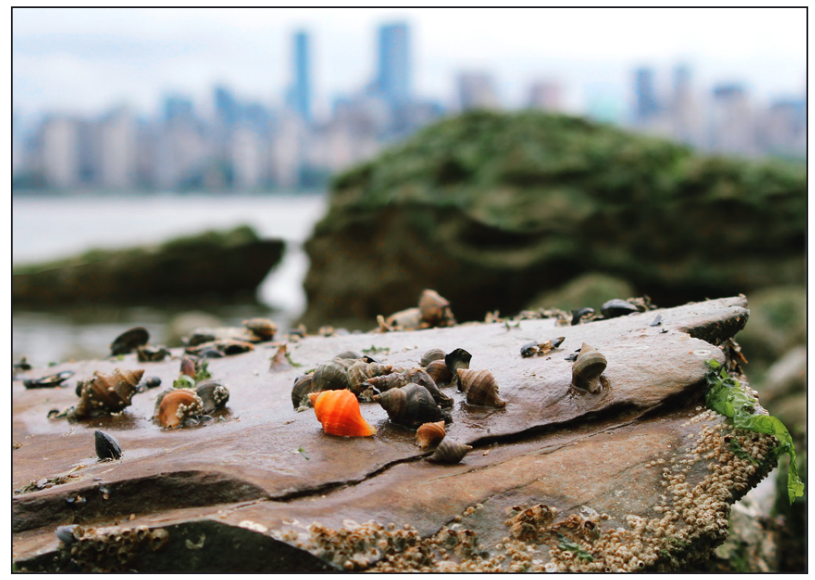

Adult and juvenile Nucella lamellosa in Burrard Inlet, British Columbia, with the Vancouver skyline in the distance.

Photo: Chris Harley

\section{INTRODUCTION}

The importance of environmental variability across scales is a persistent theme in ecology (Wiens 1986, Levin 1992, Denny et al. 2004, Jackson \& Hobbs 2009). Although our appreciation of temporal variation lags that of spatial variation (Wolkovich et al. 2014), there is ample theoretical and empirical evidence that temporal patterns of environmental variability are important drivers of ecological pattern (Vázquez et al. 2017, Ryo et al. 2019). The range of temporal environmental variability is a fundamental determinant of the distribution, abundance, and long-term persistence of species (Van Den Hoek

() The authors 2020. Open Access under Creative Commons by Attribution Licence. Use, distribution and reproduction are unrestricted. Authors and original publication must be credited. 
1982, Boyce et al. 2006, Chan et al. 2016). Local biodiversity can be related to the frequency of disturbance, the extent and predictability of seasonal environmental variability, and the spatiotemporal scale(s) at which these factors are operating (Sousa 1979, Lepori \& Hjerdt 2006, Tonkin et al. 2017). Interannual variation in factors such as temperature and rainfall can alter the availability of limiting resources, determine the nature of interactions among species, and ultimately drive long-term variation in primary production and population size (Ernest et al. 2000, Leonard 2000, Tielbörger \& Kadmon 2000). Understanding patterns of temporal variation and how aspects of this variation are changing through time are key to understanding the ecological consequences of ongoing global change (Vasseur et al. 2014, Lawson et al. 2015, Vázquez et al. 2017). Furthermore, knowledge of pre-existing evolutionary adaptations to how these patterns have historically occurred is a necessary part of this endeavor (Reed et al. 2010, Botero et al. 2015).

The effects of environmental conditions - means, extremes, and patterns of temporal variation-on populations vary across spatial gradients and across ontogenetic stages. Abiotic factors like temperature and salinity change along gradients of latitude, depth, and proximity to freshwater inputs. As a result, different populations of a species will encounter different mean conditions, as well as different degrees of seasonal and interannual fluctuations. Populations may thus respond to environmental forcing in site-specific ways, reflecting variation in conditions experienced along with any local adaptation (Zippay \& Hofmann 2010), which together determine the 'stress' experienced by individual organisms. Different life-history stages of a species may also respond differently to abiotic extremes, depending on their inherent tolerances, with implications for the age class structure of a population and long-term population growth and stability (Sorte et al. 2010, Ong et al. 2015, Nasrolahi et al. 2016). Juvenile stages of benthic invertebrates, for instance, already have high mortality rates and are especially vulnerable to the enhanced mortality effects of shifts in abiotic factors (Gosselin \& Qian 1997). To understand how a species will respond to environmental variability, it is thus important to understand the effects of abiotic conditions throughout the life cycle and at appropriate spatial and temporal scales.

Estuaries represent excellent natural systems in which to explore the ecological ramifications of complex environmental fluctuation across a range of temporal scales. In general, seasonal and interannual fluctuations in environmental variables like temperature and salinity can affect the timing and success of biological events such as reproduction (Moreno \& Møller 2011) and migration (Gibson et al. 1998), determine food availability and feeding habits (Baird 1990), and impose limitations on the abundance and spatial distribution of species (Miller et al. 2009, Douglass et al. 2020). Abiotic factors play an important role in determining the structure of estuarine populations (Miron \& Desrosiers 1990, Pérez-Castañeda \& Defeo 2004), where their fluctuations are often a part of natural tidal and seasonal cycles, and species are often locally adapted to tolerate the usual range of conditions that is encountered (Kuo \& Sanford 2009, Pearson et al. 2009). However, when stochastic events cause abiotic extremes to exceed tolerance limits of individuals for enough time, mortality events can occur (Garrabou et al. 2009, Firth et al. 2011). Global climate change is predicted to increase the variability of a number of environmental factors and increase the likelihood of extreme events and resultant mortality events (Easterling et al. 2000, Coma et al. 2009, IPCC 2013), and this has already been observed in some estuarine systems (Dolbeth et al. 2011, Winder et al. 2011). Changes in the frequency, magnitude, and predictability of extreme events may represent a challenge that will set new limitations on the ability of species to withstand and recover from fluctuations in environmental factors and may in fact trigger rapid, ecosystem-scale changes (Cloern et al. 2016).

In estuarine systems, salinity is a major driver of population dynamics and can determine size and age structure, growth rates, and local abundance (Deegan 1990, Westerbom et al. 2002, Douglass et al. 2020). There are several important spatial and temporal trends in salinity variation. Estuarine salinity varies with the rate of freshwater input relative to the rate of flushing, and with mixing and distance to the freshwater source. Because freshwater runoff from rivers creates an unmixed low salinity layer on the ocean's surface, establishing a strong halocline, salinity also varies strongly with depth. As a result, the potential distribution, abundance, and performance of certain estuarine species can be related to position relative to freshwater inputs and to depth (Lougee et al. 2002, Barletta et al. 2005, Tolley et al. 2005). These ecological patterns are not static, however, as both horizontal and vertical salinity gradients change over multiple time scales. In macro-tidal systems, benthic organisms can experience rapid and repeated changes in salinity as the halocline moves up and down with the tides, and their ability to per- 
sist in such variable conditions depends on their ability to either tolerate or avoid periods of unfavorable salinities. Gastropods, for example, can withdraw into their shells and suppress respiration to withstand periods of low salinity that would otherwise kill them (Shumway 1979). Seasonal declines in coastal estuarine salinity following increased freshwater runoff and/or increased precipitation can impose limits to the growth of populations, mediate interspecific interactions, and force organisms to migrate, locally adapt/acclimatize, or suffer high mortality (Dunson \& Travis 1991, Witman \& Grange 1998, Verdelhos et al. 2015, Douglass et al. 2020). Seasonal variations in runoff, precipitation, and tides create a dynamic low salinity layer that will affect intertidal and shallow subtidal organisms differentially, depending on the duration and time history of exposure, as well as the extent to which they can physiologically acclimatize to osmotic stress, avoid it in situ through behavioral mechanisms, or migrate to remain within a preferred environmental salinity range (Drouin et al. 1985, Bennett et al. 2002, Agüera et al. 2015).

To explore salinity as a complex driver of marine population structure across a variety of spatial and temporal scales, we have examined the consequences of tidal and interannual salinity variation on multiple life stages of the muricid gastropod Nucella lamellosa. N. lamellosa is a predatory whelk commonly found in lower intertidal and shallow subtidal regions of the northeast Pacific Ocean. It is an aggregate breeder and often returns to the same site to spawn every year, moving higher in the intertidal to do so (Spight 1974). It deposits its embryos in stalked egg capsules, containing about 20-80 embryos each, during the late winter and early spring, with developmental periods of around 3-5 mo in the field (Connell 1970, Lambert \& Dehnel 1974, Spight 1974). Like other gastropods, individuals in the genus Nucella are able to withdraw into their shells to escape shortterm low salinity events, but they are poor volume regulators, so when long periods of exposure below 15 psu exceed their ability to remain withdrawn, this may represent a significant threat (Johannsson 1971, Stickle et al. 1985). Salinity stress is also known to cause mortality in $N$. lamellosa embryos, although their egg capsules provide some degree of short-term protection (Pechenik 1982). Because of the overlap of embryonic developmental periods and high river outflow in the spring and summer, understanding the effect of salinity on the mortality and development of encapsulated embryos, in combination with adult and juvenile tolerances, is key to understanding how salinity structures $N$. lamellosa populations and their distribution, and the implications of projected change. Finally, because N. lamellosa is a direct developer with crawl-away juveniles, limited dispersal ability, and thus a greater potential for local adaptation (Yamada 1989), it is possible that $N$. lamellosa populations that regularly encounter low salinities are locally adapted to such conditions due to natural selection combined with limited gene exchange with other populations. These factors make $N$. lamellosa an ideal subject for studying the relationship between variation in environmental factors and population structure.

We examined N. lamellosa populations in the Strait of Georgia, which forms part of the Salish Sea in southwestern British Columbia, Canada, and northwestern Washington State, USA. The Salish Sea is a large and biologically productive estuarine system and one of the world's largest inland seas. The largest source of freshwater is the Fraser River, which flows into the southern Strait of Georgia (Fig. 1). Snowmelt in its $234000 \mathrm{~km}^{2}$ drainage basin is the primary driver of the Fraser River freshet, and peak flows in late spring/early summer can exceed $12000 \mathrm{~m}^{3} \mathrm{~s}^{-1}$ (Riche et al. 2014). Patterns of salinity within the Strait of Georgia vary spatially with distance from the mouth of the Fraser River, and both seasonally and interannually with patterns of river discharge (Ward 1976, Chapman \& Brinkhurst 1981, Halverson \& Pawlowicz 2008). We conducted a combination of field surveys and lab experiments to establish (1) the relationships between salinity and $N$. lamellosa abundance and population structure in space and time, (2) the relative vulnerability of embryos, juveniles, and adults to hyposaline conditions, (3) the importance of constant vs. variable salinity conditions, and (4) the relevance of local acclimatization and/or adaptation in mitigating the effects of low salinity.

\section{MATERIALS AND METHODS}

\subsection{Study sites}

We conducted surveys of Nucella lamellosa populations at 11 sites in the southern Strait of Georgia that differed in their exposure to the Fraser River plume (Fig. 1, Table S1 in the Supplement; www.int-res.com/ articles/suppl/m643p001_supp.pdf). Seven of the 11 sites were situated near the river mouth, in and around the entrance to Burrard Inlet and could be classified as 'low salinity', where localized salinity seasonally drops below 15 psu during peak Fraser River outlfow: Tower 


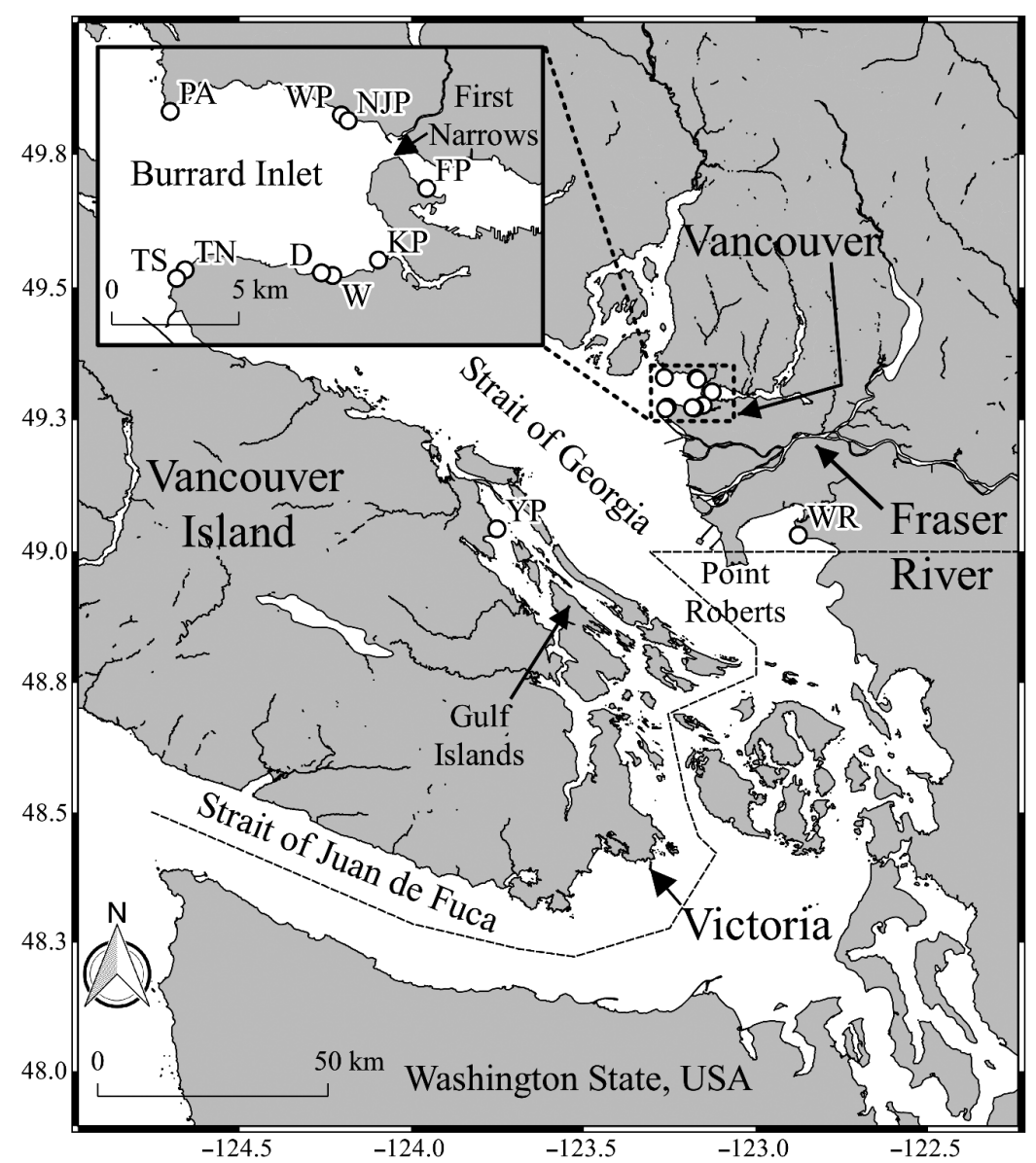

Fig. 1. Eleven study sites (open circles) used in abundance surveys and for collection of egg capsules and juvenile and adult Nucella lamellosa: Tower Beach South (TS), Tower Beach North (TN), Dunbar (D), Waterloo (W), Kitsilano Point (KP), Figurehead Point (FP), Navvy Jack Point (NJP), Weston Park (WP), Point Atkinson (PA), White Rock (WR), and Yellow Point (YP)

Beach South, Tower Beach North, Dunbar, Waterloo, and Kitsilano Point on the southern shore of the inlet, and Weston Park and Point Atkinson on the northern shore. We classified the remaining 4 sites as 'high salinity', where salinity tends to not drop below 15 psu. Further east and on the northeast side of Stanley Park the topographic constriction of the First Narrows partially shields Figurehead Point from the river plume. Near Weston Park, tidal outflow from east of First Narrows bathes Navvy Jack Point, and it is thus somewhat intermediate in salinity but nonetheless saltier than the low salinity sites. Finally, 2 sites that are distant from the mouth of the Fraser River are White Rock, protected from the river plume by Point Roberts, and Yellow Point, across the Strait of Georgia and protected from the plume by the Gulf Islands. See Halverson \& Pawlowicz (2008) for a snapshot of summer salinity patterns in the study area.
Geologically, most sites were a mix of cobble and boulder except for Point Atkinson (granitic bedrock), Yellow Point (sandstone bedrock), and Dunbar and Waterloo (sandstone overlain with cobble and boulder). These habitat types were continuous from the high intertidal to the subtidal, allowing for potential vertical migration by $N$. lamellosa to escape seasonally low salinity surface waters at all sites, with the exception of Tower Beach North, which featured an extensive sand flat from the very low intertidal into the subtidal. Biologically, all sites were typical of protected intertidal shores in the Salish Sea. Barnacles and mussels were the dominant prey items in the mid-to-low intertidal zone. In addition to $N$. lamellosa, other predators included juvenile Dungeness crabs (Metacarcinus magister; authors' pers. obs.) and sea stars (Pisaster ochraceus and Evasterias troschelii; see Kay et al. 2019).

\subsection{River outflow and salinity}

We measured salinity at individual sites from 2008-2014 (we did not sample all sites prior to 2011) in a haphazard fashion, according to when we were conducting fieldwork in the area. As such, we sampled some sites more than others, with Dunbar receiving the most measurements ( $\mathrm{n}=57$ ), and Point Atkinson the fewest $(\mathrm{n}=6)$. At all sites, we took measurements throughout the year, rather than during a particular season. We conducted salinity measurements using a hand-held refractometer.

\subsection{Field distribution patterns}

We estimated $N$. lamellosa densities in the spring generally, mid-April to mid-May-2011-2014 after most dogwhelk breeding aggregations had dispersed but before seasonally low salinity levels resulted in mortality or emigration from the intertidal zone. We surveyed $N$. lamellosa abundance in $2 \times 5 \mathrm{~m}$ areas by laying out a $5 \mathrm{~m}$ measuring tape and recording all live and dead (shells that were intact but empty or occupied by hermit crabs) $N$. lamellosa found within $1 \mathrm{~m}$ of the tape. We surveyed 4 such transects at each site, except for at Navvy Jack Point, where we only 
consistently surveyed 2 transects due to time constraints. We positioned the transects parallel to the shore in the areas where the highest dogwhelk abundance occurred: the low intertidal at most sites but in the mid-intertidal at Lighthouse Park and Yellow Point. Within each transect, we counted all live dogwhelks and characterized them as adults $(\geq 30 \mathrm{~mm}$ total length) or juveniles ( $<30 \mathrm{~mm}$ total length). Historically, N. lamellosa from a nearby site (Friday Harbor, Washington, USA) have been reported to became reproductively mature between 25 and $30 \mathrm{~mm}$, with individuals that hatched the previous year seldom exceeding $25 \mathrm{~mm}$ in length by April (Spight 1974). However, dogwhelks in other populations, including those we surveyed, appeared to grow more rapidly and attain larger adult sizes than the dogwhelks at Friday Harbor (Spight 1981). Furthermore, some additional growth may have occurred between April, when Spight sampled, and some of our May sampling dates. Therefore, we used $30 \mathrm{~mm}$ as the cut-off between $\sim 1$ yr old juveniles and older adults. We also counted shells that were empty or contained hermit crabs and binned them into adult and juvenile size classes using the same $30 \mathrm{~mm}$ cut-off. Although we do not know the 'lifespan' of a dead Nucella shell before it is degraded, destroyed, or removed from the system, we assume that empty or hermit crab-occupied shells are a good proxy for recent $N$. lamellosa mortality as there is good evidence in support of this assumption for another whelk species (Laptikhovsky et al. 2016). Young-of-the-year (i.e. those individuals less than a few months old by the sampling date) were too small and cryptic to appear in our censuses.

\subsection{Salinity tolerance of encapsulated embryos}

We collected $N$. lamellosa egg capsules from a large breeding aggregation located on the face of a large boulder from the Dunbar site in January 2012 (surface salinity was $29 \mathrm{psu}$ ). The embryos in all capsules were small and in early stages of development. Egg capsules were acclimated for $1.5 \mathrm{wk}$ in a seawater table held at $11^{\circ} \mathrm{C}$ and $33 \mathrm{psu}$. We then placed a total of 100 randomly selected egg capsules into treatments of $9,12,15,20$, and 25 psu (4 replicates of each, 5 egg capsules per replicate, see Text S1 and Fig. S1 in the Supplement) for a total of $77 \mathrm{~d}$. We checked the egg capsules every 3-9 d during this period. $N$. lamellosa embryos take on a purple or pink colouration when undergoing physiological stress and at high risk of mortality (Spight 1975,
Pechenik 1982). As such, we recorded an egg capsule as showing signs of stress if it acquired purple colouration that lasted the duration of the study without return to a normal colour. We also recorded any hatching of the egg capsules, signaled by a broken capsule plug and hatchlings visible in the experimental containers. We visually assessed the egg capsules using a dissecting microscope on the $77^{\text {th }}$ day of the experiment. A small number of egg capsules ruptured over the course of the study due to handling, and we removed them from the analysis.

\subsection{Salinity tolerance of juveniles and adults}

The goals of this portion of the study were to compare the relative differences in salinity tolerance of $N$. lamellosa adults and juveniles, as well as individuals living in areas that either do or do not experience seasonal low salinities. We also explored how the daily tidal cycle might provide some relief from low salinity stress during a freshet. We collected N. lamellosa from Tower Beach South and White Rock in early June 2012. We collected adults from both sites ( $\mathrm{n}=96$ from Tower Beach South; $\mathrm{n}=132$ from White Rock), along with juveniles $(n=144)$ from White Rock. $N$. lamellosa found at Tower Beach South were larger than those at White Rock, with very few smaller individuals present at Tower Beach South and few very large ( $>45 \mathrm{~mm}$ ) individuals present at White Rock. All individuals were acclimated for $1 \mathrm{wk}$ in a seawater table at $12^{\circ} \mathrm{C}$ with a salinity of $30 \mathrm{psu}$. During this period, we allowed the snails to feed on mussels to satiation. The $N$. lamellosa individuals from each site and age class were then placed into 4 replicates each of 3 salinity treatments: constant 20 psu (high salinity), constant 9 psu (low salinity), and 9 psu with daily, $3 \mathrm{~h}$ exposure to $20 \mathrm{psu}$ (variable salinity) (see Text S1 and Fig. S1). We chose 20 psu as a 'high' salinity as it represents a commonly encountered condition during the Fraser River freshet for all N. lamellosa living in the Strait of Georgia (Fig. 2). We ran the experiment for $21 \mathrm{~d}$ to simulate a feasible period of low salinity stress for $N$. lamellosa living near the mouth of the Fraser River. As seen in the results of the site-level salinity modeling (presented in Section 3.1), this is well within the number of days of $<9$ psu salinity that can occur at Tower Beach South. We used the variable salinity treatment to simulate what would happen during high tide, when the low salinity surface layer would move above the range of $N$. lamellosa and offer relief from exposure to low salinity. While this 'tidal' pattern is not perfectly representa- 


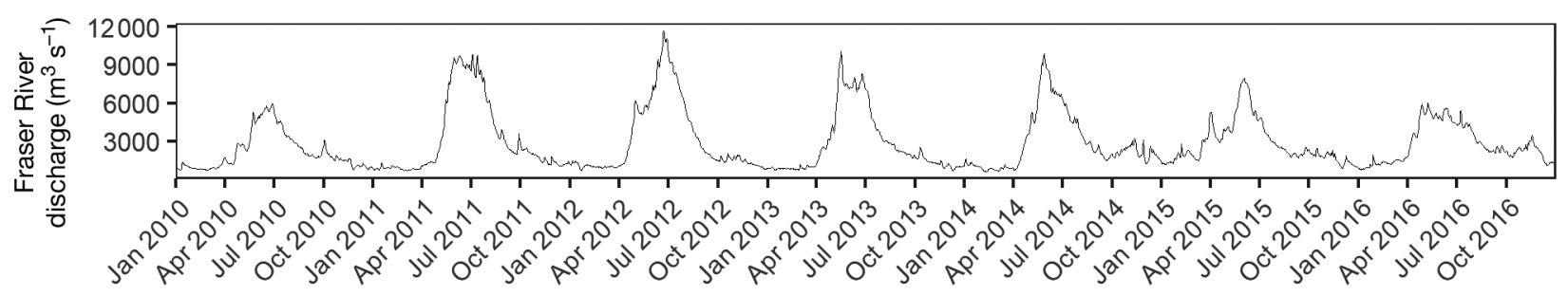

A

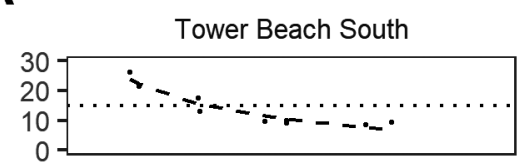

Dunbar

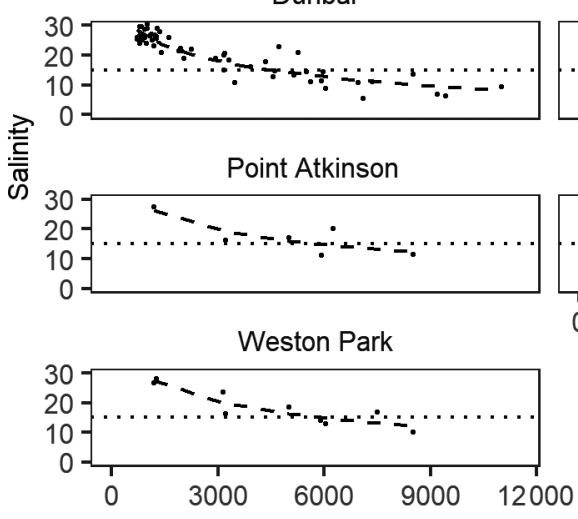

Low Salinity Sites

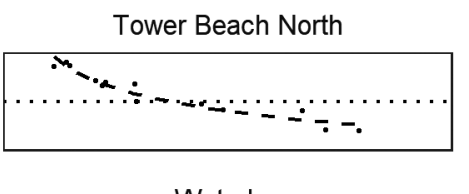

Waterloo
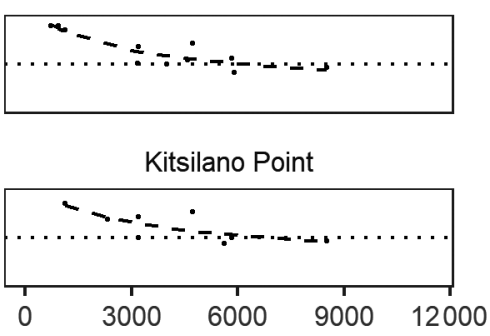

Fraser River discharge $\left(\mathrm{m}^{3} \mathrm{~s}^{-1}\right)(-4 \mathrm{~d}$ lag)
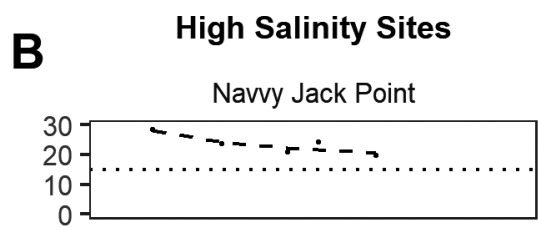

Figurehead Point

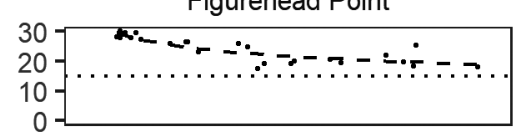

White Rock
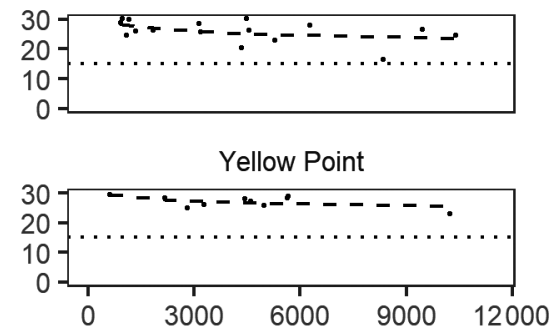

Fig. 2. Daily Fraser River outflow as measured at the Hope, BC, hydrographic station (top) during 2010-2016, and salinity observations (bottom) in relation to the total outflow of the Fraser River, measured $4 \mathrm{~d}$ prior at Hope. Observed data plotted as points; predicted data (according to the mixed-effects model fit to observed salinity data, with 4 d prior Fraser River outflow as a predictor, site as random effect with varying slope and intercept, and accounting for temporal autocorrelation) plotted as dashed curves. The (A) 'low' salinity sites are those where predicted salinity dropped below 15 psu (straight, dotted line), below which salinity acts as a stressor for Nucella lamellosa, compared to the (B) 'high' salinity sites, where this did not occur

tive of the variation in exposure to a low salinity layer that $N$. lamellosa would experience over a tidal cycle (see Text S1 and Fig. S2 in the Supplement), it was assumed to be a good approximation of the amount of daily relief that would occur (for instance, assuming the animals were at $0 \mathrm{~m}$, with a $4 \mathrm{~m}$ deep low salinity layer and a $5 \mathrm{~m}$ tidal range), and appropriate as a standardized procedure for measuring the presence or absence of a response.

Mortality was determined by visually inspecting individuals and tugging gently on their operculum with forceps. We deemed individuals to have died when they were extruding from their shells and were both unresponsive and unresisting. In some cases, opercula would easily detach from the body, indicating death and tissue decomposition. We removed any individuals from the experiment that we suspected to be dead and placed them in 30 psu seawater overnight. Any that proved to still be alive after $24 \mathrm{~h}$ we then removed from the analysis. The overall number of individuals that we excluded from the experiment because of miss-categorization of mortality was low $(n=6)$ and never exceeded 1 in any single container.

\subsection{Statistical analyses}

All statistical analyses were carried out using $\mathrm{R}$ v3.5.3 (R Core Team 2019). Statistical methodologies for each phase of the research are described below.

\subsection{River outflow and salinity analysis}

Daily salinity as a function of Fraser River outflow was predicted at each of the 11 sites using salinity observations, ln-transformed, 4 d prior Fraser River outflow, as measured at the Hope hydrographic sta- 
tion (Government of Canada 2019), and a linear model using the gls function in the package nlme (Pinheiro et al. 2018). We used total daily outflow at $4 \mathrm{~d}$ prior to the sampling date as this time lag represents the strongest correlation between Fraser River outflow and nearshore salinity in the vicinity of Burrard Inlet (S. Allen pers. comm., using the oceanographic model presented in Soontiens et al. 2016). First, our linear model was run with observed salinity values at the 11 sites as the response variable, natural log-transformed Fraser River outflow (daily total from $4 \mathrm{~d}$ prior) and site as predictor variables, and including an interaction between Fraser River outflow and site to allow for different slopes for the relationship between outflow and salinity at the different sites. We accounted for temporal autocorrelation by using an autoregressive process of order one (corAR1). The model fit appears in Fig. 2. Next, we used historical, daily data of Fraser River outflow measured at the Hope station (Government of Canada 2019) to estimate daily salinity at each of the 11 sites using the previously identified model (Fig. 3). Finally, we calculated a yearly salinity stress metric for $N$. lamellosa populations at each site by taking the inverse $\ln$ of the sum of all the daily salinities predicted at each site for each year.

\subsection{Distribution patterns analysis}

All population models were fit using the glmmTMB function in the glmmTMB package (Brooks et al. 2017). In all models, the stress metric was centered and scaled (around the mean and according to $1 \mathrm{SD}$ ), and the metric from the previous year was used under the assumption that the springtime population counts would reflect population changes that had occurred during the previous season of increased Fraser River outflow. We modelled $N$. lamellosa abundance at each site in relation to the calculated stress metric from the previous year using a generalized linear model (GLM), assuming a negative binomial error structure and a log-link function, with stress metric, site, and the interaction between the 2 variables set as predictors. Year was initially specified as a random effect in a mixed-effects model, but its removal improved model fit according to second-order Akaike information criterion (AICc) comparison, assessed using the package MuMIn (Barton 2018). We modelled the proportion of shells that were empty vs. alive at each site in relation to the calculated stress metric, using a generalized linear mixed-effects model (GLMM), assuming a binomial error structure and a complementary log-log (cloglog) function. We speci-
A
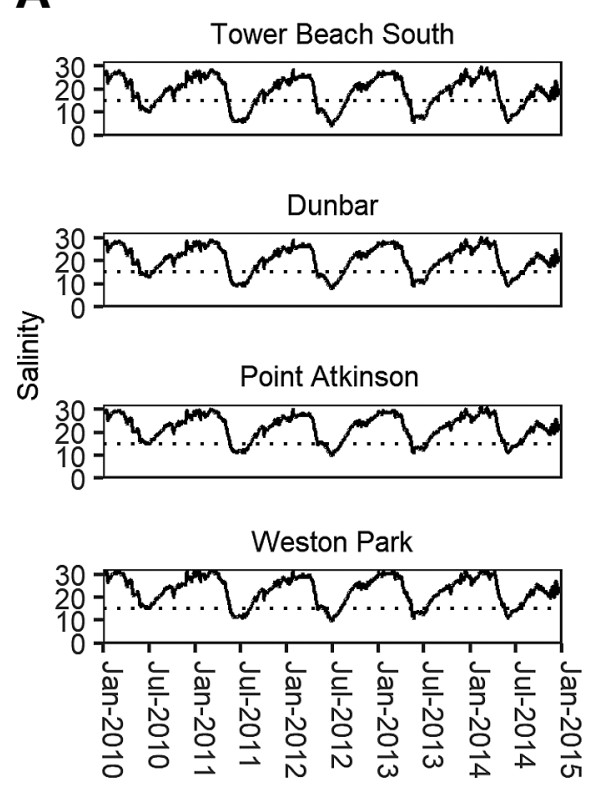

\section{Low salinity sites}
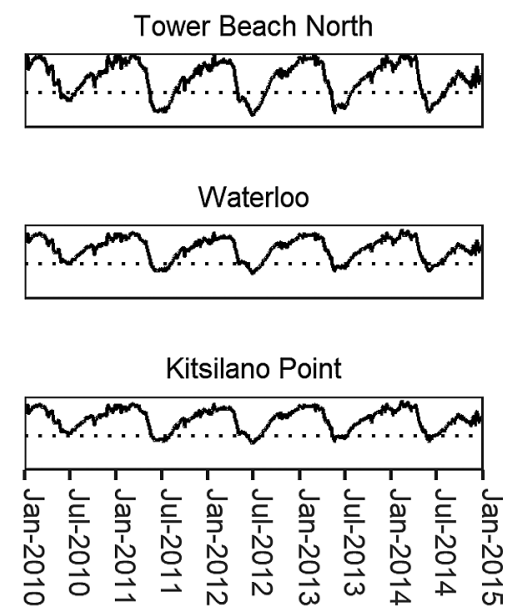

Date
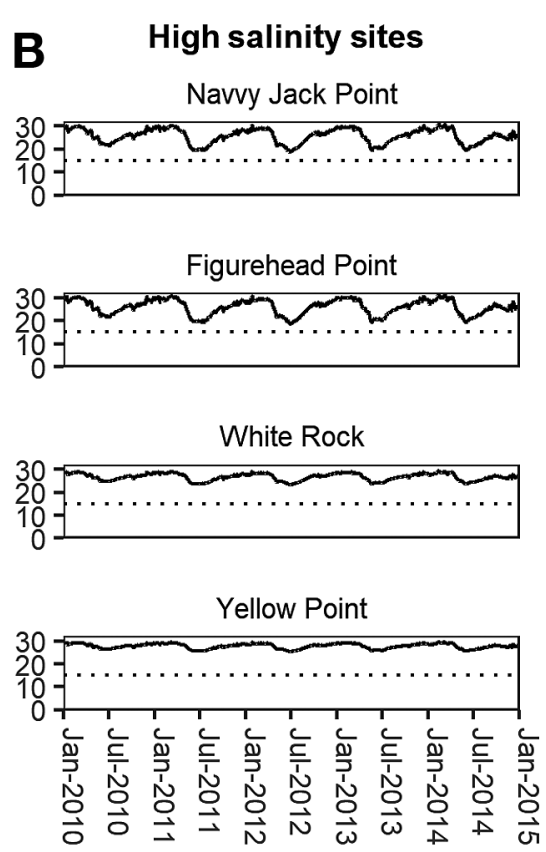

Fig. 3. Reconstructed daily salinity at each of the 11 field sites as predicted according to the mixed-effects model fit to observed salinity data, with 4 d prior Fraser River outflow as a predictor, site as random effect with varying slope and intercept, and accounting for temporal autocorrelation. At (A) 'low' salinity sites, predicted salinity dropped below the threshold at which hyposalinity stress becomes important for Nucella lamellosa (15 psu, straight dotted line) during the freshet, which did not occur at the (B) 'high' salinity sites 
fied site, nested in year, as random effects with fixed slope. We modelled the proportion of live individuals that were juveniles (2012-2014 only) in relation to stress index using a GLM with binomial error structure and a logit-link function. We initially specified site, nested in year, and year as random effects with fixed slopes in a GLMM, but they were removed from the model after AICc comparison.

\subsection{Effects of salinity on embryonic stress, and juvenile and adult survival analysis}

We used survival analysis (Muenchow 1986) to determine the effects of salinity on signs of stress within egg capsules, as well as to determine the effect of population, age-class, and salinity on mortality over time for the adult and juvenile $N$. lamellosa data. We used the survival package for survival analysis (Therneau 2015, Therneau \& Grambsch 2015), and the coxme package for mixed-effects Cox Proportional Hazard models (CPH) (Therneau 2019). The response variables considered in survival analysis are time and event status, in this case day of observation and whether purple discolouration (egg capsules) or death (adults/juveniles) has occurred. Some of the data in the adult and juvenile trials were right censored, as some individuals were still alive on the final day of the study. We defined the first day of the manipulation as day zero for each experiment. We used Kaplan-Meier survival curves (Kaplan \& Meier 1958) to visually assess trends in survivorship over the course of each study. We used a single mixed-effects $\mathrm{CPH}$ model (coxme function) to determine the influence of salinity treatment on risk of purple colouration present in a single egg capsule as an indicator of stress, with beaker nested within block as a random effect. To determine the effect of treatment, age/population, and body size on the survival of the $N$. lamellosa adults and juveniles, we used a mixed-effects $\mathrm{CPH}$ model with shell length, population/age class (Tower Beach South adults, White Rock juveniles, and White Rock adults), and treatment (low, high, variable) as predictor variables, and with tank as a random effect. We did not consider the high salinity treatment tanks because all individuals, excluding one White Rock adult, survived until the end of the experiment. To further explore the effect of population on salinity tolerance we used the lme function in the nlme package to run a linear mixed effects model (LMM) for just the low salinity treatment individuals. We specified date of death as the response variable, shell length (centered and scaled around the mean and 1 SD), population
(White Rock vs. Tower Beach South), and the interaction between shell length and population as predictors, tank as a random effect, and a variance structure (varIdent) allowing each population to have a different variance.

\section{RESULTS}

\subsection{Salinity}

Salinity data collected from the field demonstrated that Tower Beach South, Tower Beach North, Dunbar, Waterloo, Point Atkinson, Kitsilano Point, and Weston Park could all be characterized as low salinity sites (i.e. they regularly experienced seasonal salinities below 15 psu), while Navvy Jack Point, Figurehead Point, White Rock, and Yellow Point could all be characterized as high salinity sites (i.e. they did not regularly experience seasonal salinities below $15 \mathrm{psu}$ ) (Fig. 3). The salinity predictions for 2010-2014 that were estimated using the linear model, based on daily Fraser River outflow data, suggests that in 2010 most sites did not experience salinities much below 15 psu but that in 2011, 2012, 2013, and 2014 salinities below 15 psu were reached at all 'low salinity sites', and salinities of 9 psu or less were reached in these years at both Tower Beach sites and at Dunbar (Table 1). According to the salinity stress metric, as calculated from modelled salinity data (Fig. 4), it appears that 2011 and 2012 may have been the most stressful years in terms of low salinity conditions, followed by 2013 and 2014, with 2010 being a year of minimal low salinity stress for these Nucella lamellosa populations.

\subsection{N. lamellosa population abundance and structure in relation to salinity}

Populations at low salinity sites generally decreased from 2011 to 2012 and 2013, but there was some recovery in 2014 (Fig. 5). The Tower Beach North population appeared to be locally extinct during 2012-2014. In contrast, the 4 high salinity populations each peaked in a different year. At Figurehead Point, there was a surge in population size in 2014, although this may be in part due to continued recovery from local extinction due to tributyltin (TBT) pollution (Horiguchi et al. 2004, Thompson et al. 2005). For the low salinity populations closest to the mouth of the Fraser River (Tower Beach South and North, Dunbar, and Waterloo) the proportions of the populations that were juveniles remained low during 
Table 1. Total days of salinity $<15$ and $<9$ psu at each of 11 sites for 2010-2014, as estimated by linear model with 4 d prior Fraser River outflow as a predictor

\begin{tabular}{|c|c|c|c|c|c|c|c|c|c|c|}
\hline \multirow[t]{2}{*}{ Site } & \multicolumn{2}{|c|}{$2010-$} & \multicolumn{2}{|c|}{$-2011-$} & \multicolumn{2}{|c|}{$-2012-$} & \multicolumn{2}{|c|}{-2013} & \multicolumn{2}{|c|}{-2014} \\
\hline & $<15 \mathrm{psu}$ & $<9 \mathrm{psu}$ & $<15 \mathrm{psu}$ & $<9$ psu & $<15 \mathrm{psu}$ & $<9 \mathrm{psu}$ & $<15 \mathrm{psu}$ & $<9 \mathrm{psu}$ & $<15$ psu & $<9 \mathrm{psu}$ \\
\hline Tower Beach South & 71 & 0 & 112 & 70 & 120 & 54 & 94 & 58 & 104 & 36 \\
\hline Tower Beach North & 58 & 0 & 95 & 61 & 111 & 40 & 77 & 17 & 90 & 19 \\
\hline Dunbar & 46 & 0 & 91 & 0 & 107 & 12 & 71 & 1 & 77 & 0 \\
\hline Waterloo & 0 & 0 & 75 & 0 & 63 & 0 & 60 & 0 & 47 & 0 \\
\hline Point Atkinson & 3 & 0 & 83 & 0 & 74 & 0 & 62 & 0 & 54 & 0 \\
\hline Kitsilano Point & 0 & 0 & 69 & 0 & 53 & 0 & 56 & 0 & 28 & 0 \\
\hline Weston Park & 0 & 0 & 83 & 0 & 68 & 0 & 61 & 0 & 49 & 0 \\
\hline Navvy Jack Point & 0 & 0 & 0 & 0 & 0 & 0 & 0 & 0 & 0 & 0 \\
\hline Figurehead Point & 0 & 0 & 0 & 0 & 0 & 0 & 0 & 0 & 0 & 0 \\
\hline White Rock & 0 & 0 & 0 & 0 & 0 & 0 & 0 & 0 & 0 & 0 \\
\hline Yellow Point & 0 & 0 & 0 & 0 & 0 & 0 & 0 & 0 & 0 & 0 \\
\hline
\end{tabular}

A

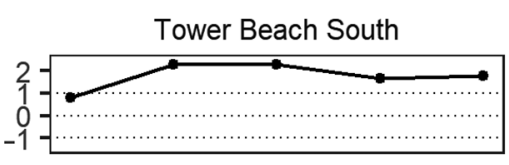

Dunbar

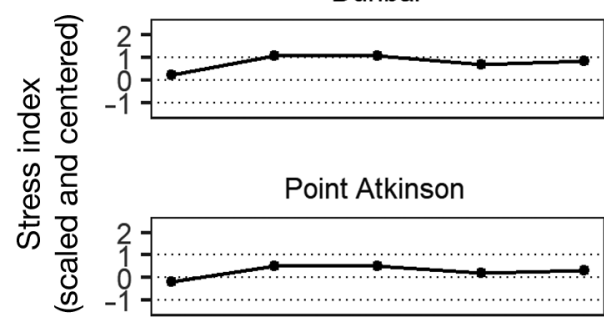

Weston Park

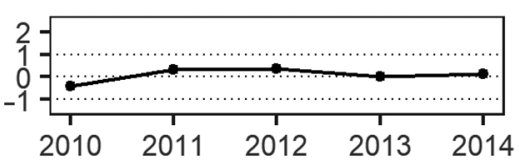

B High salinity sites

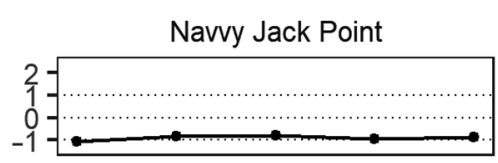

Figurehead Point

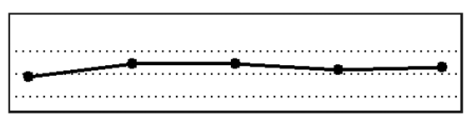

Kitsilano Point

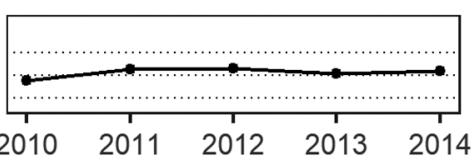

$2010 \quad 2011 \quad 2012 \quad 2013 \quad 2014$

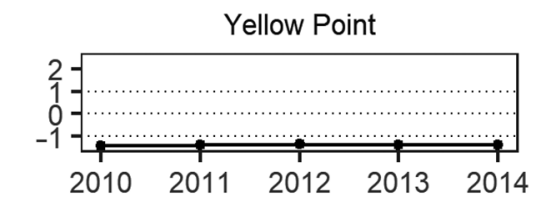

Year

Fig. 4. Calculated salinity stress index (scaled and centered according to the mean and 1 SD, represented by dotted lines) for the 11 field sites for 2010-2014

2012-2014 (Fig. 6). At more distant low salinity sites (Point Atkinson, Kitsilano Point and Weston Park) the proportions of juveniles declined from 2012-2013, with some recovery at Kitsilano Point in 2014. At the high salinity sites, the proportions of the populations that were juveniles were highest in 2014, except for Yellow Point, where they were highest in 2012.

Site, year-prior salinity stress index, and the interaction between the 2 terms significantly predicted $N$. lamellosa abundances ( $\mathrm{p}<0.001$ for all terms, Fig. 7). Plotting the model predictions against the observed values suggests that increasing stress index was associated with decreasing $N$. lamellosa abundances at all sites deemed to be low salinity, except for Weston Park. This is interesting, considering that this site experienced similar salinities to Waterloo over the years, although somewhat higher salinities in the winter at Weston Park led to lower annual stress indices. At White Rock and Yellow Point, stress hardly varied year to year, and the relationship between abundance and stress was positive, possibly due to chance or other factors not measured here. Figurehead Point and Navvy Jack Point also interestingly showed a negative relationship between abundance and salinity stress, however. The slope of the relationship across sites did not seem to relate to the 


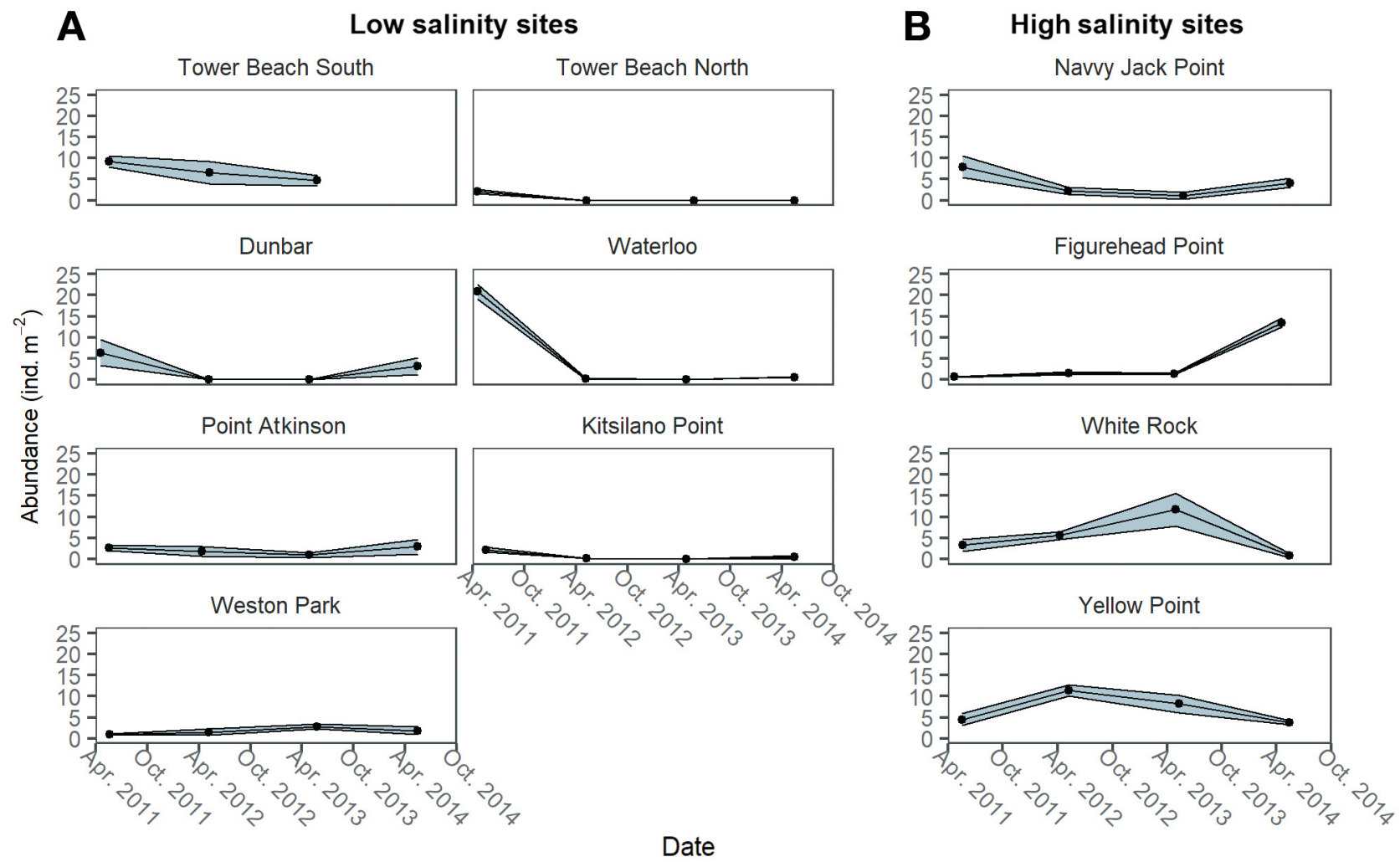

Fig. 5. Nucella lamellosa average abundance (ind. $\mathrm{m}^{-2}$ ) as measured at 11 field sites during 2011-2014. Points connected by lines indicate average abundance across transects; upper and lower limits to the coloured ribbons indicate the SEM. Sites are divided according to whether spring/summer salinity can be classified as 'low' or 'high'

\section{A}

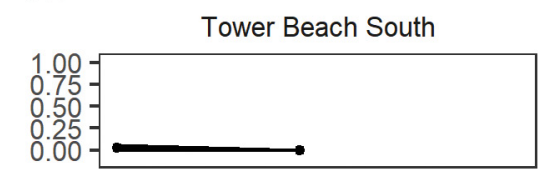

Dunbar
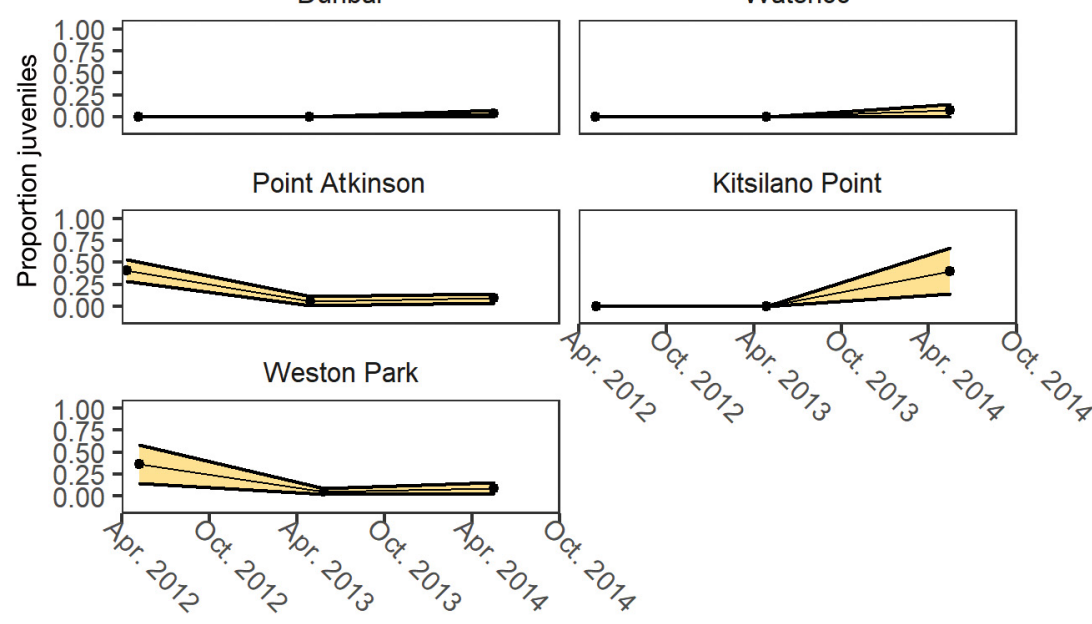

Date
B High salinity sites

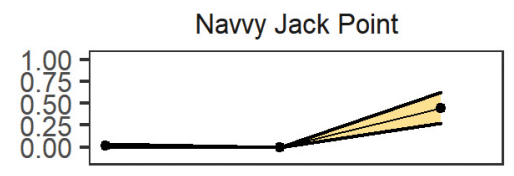

Figurehead Point

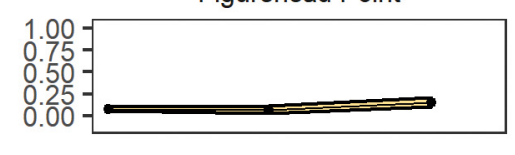

White Rock

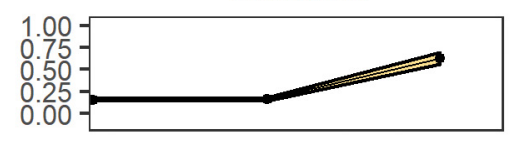

Yellow Point

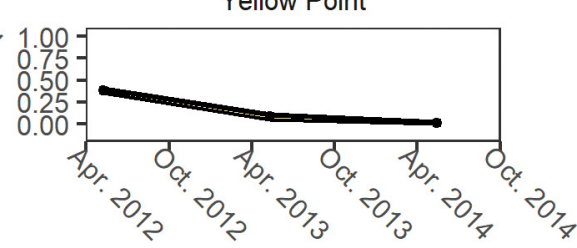

Fig. 6. Proportion of Nucella lamellosa populations represented by juveniles (<30 mm shell length) at 11 field sites, separated by 'low' or 'high' salinity classification. Points connected by lines indicate average percentage across transects; upper and lower limits to the coloured ribbons indicate SEM 


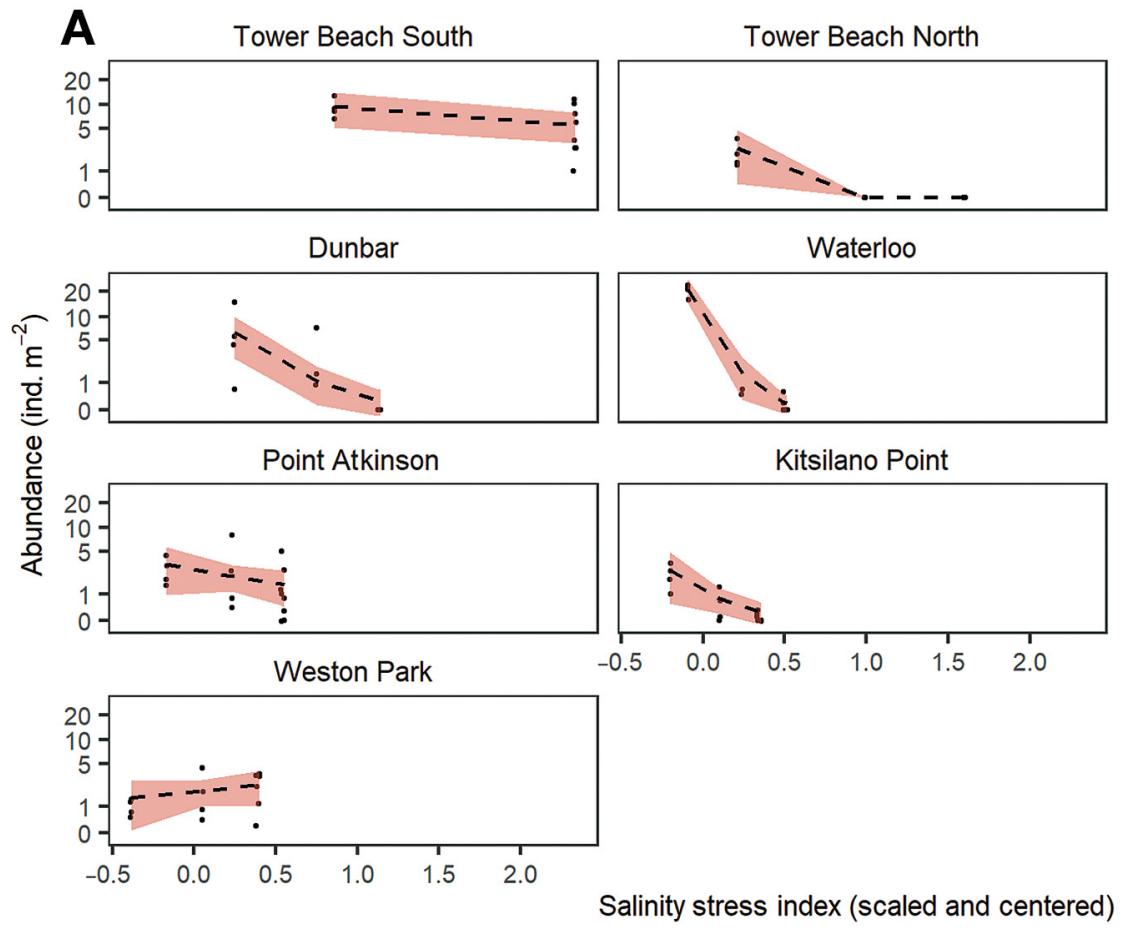

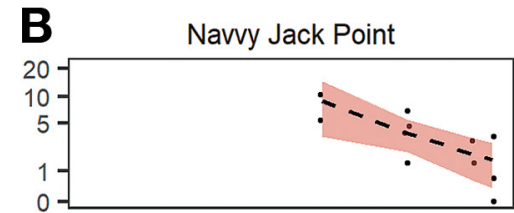

Figurehead Point
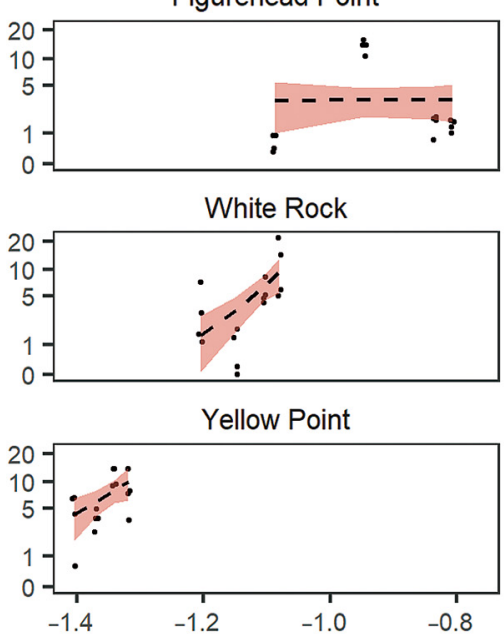

Fig. 7. Negative binomial generalized linear model (GLM) predictions for the model relating Nucella lamellosa population abundances (ind. $\mathrm{m}^{-2}$, plotted on a logarithmic scale) to an index of salinity stress experienced by the various populations during 2011-2014, plotted on top of observed values. Actual data are plotted as points (jittered to increase visibility); model predictions are plotted as the dashed lines, with the ribbons indicating $95 \%$ confidence intervals. The stress index is scaled and centered around the mean and SD of all values

magnitude of the stress index, indicating that while salinity variation is a strong driver of abundance trends in general, there are other factors at play that influence the importance of salinity across sites.

Higher salinity stress index in the previous year led to an increase in of the proportion of $N$. lamellosa counted that were dead, but with high variation among sites ( $p=0.03$, Figs. 8 \& 9B). A higher salinity stress index in the previous year was also linked to decreasing proportions of juveniles at the low salinity site populations ( $p=0.002$, Fig. 9A). The variance around the predicted juvenile proportions was very large, likely due to the limited data set and variation of other factors by site. Also, a lack of age class data for 2011 severely decreases the ability of the model to make predictions, given the large declines in population that occurred for many sites between 2011 and 2012.

\subsection{Encapsulated embryo tolerance in the laboratory}

The first occurrence of purple colouration in $N$. lamellosa embryos appeared in the 9,12 , and $15 \mathrm{psu}$ salinity treatments after a mean of $17.5 \pm 11.8,29.8 \pm$
11.8 , and $41.9 \pm 5.1 \mathrm{~d}$ (mean $\pm \mathrm{SD}$ ), respectively. A small fraction of the egg capsules in the 20 or 25 psu treatments developed purple colour, but the colouration had always disappeared by the next point of observation. The egg capsules in the 3 lowest salinity treatments all showed full or partial purple colouration of their embryos by the end of the study. All egg capsules in all replicates showed purple colouration after $33 \mathrm{~d}$ at $9 \mathrm{psu}, 48 \mathrm{~d}$ at $12 \mathrm{psu}$, and $77 \mathrm{~d}$ at $15 \mathrm{psu}$ (Fig. 10). Kaplan-Meier survival curve estimates show that $50 \%$ of egg capsules showing signs of stress occurred after 19,31, and $40 \mathrm{~d}$ in the 9, 12, and 15 psu treatments, respectively. According to the $\mathrm{CPH}$ model, treatment was a significant predictor of purple colouration $(\mathrm{p}=0.005)$. The $\mathrm{CPH}$ model predicted that while 12 psu would produce a slightly higher hazard ratio than $15 \mathrm{psu}$, the 9 psu treatment produced a hazard (risk of stress) that was approximately 6 times greater than at 12 psu and 31 times greater than at 15 psu.

Hatching success varied with salinity treatment. At 25 psu, we observed hatching as early as Day 31, all but 1 of the egg capsules had hatched by Day 52, and all had hatched by Day 77. We did not observe hatching in the other treatments during the experiment. However, when we transferred the egg capsules to 
A
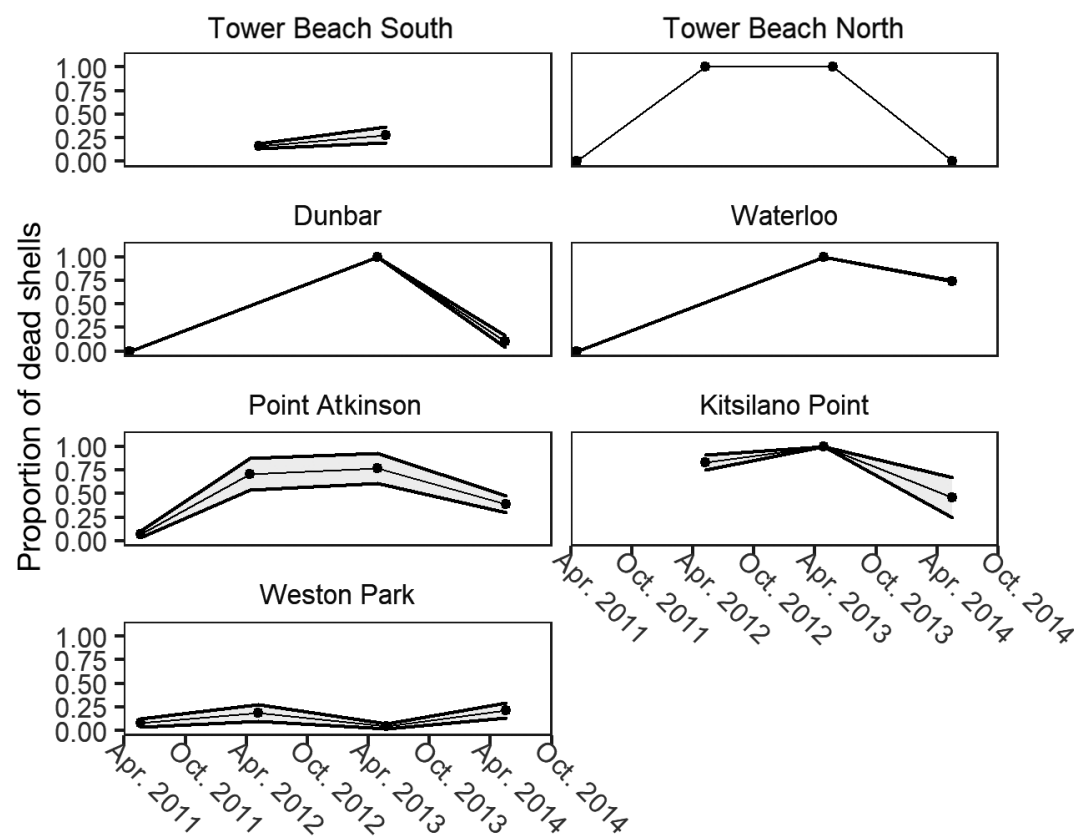

Tower Beach North

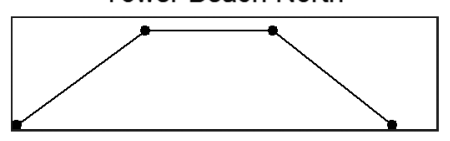

Waterloo

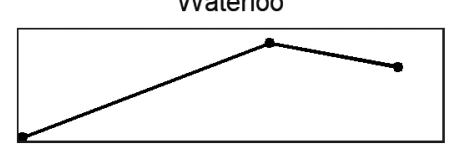

Kitsilano Point

$\mathrm{CO}^{7}$
B High salinity sites

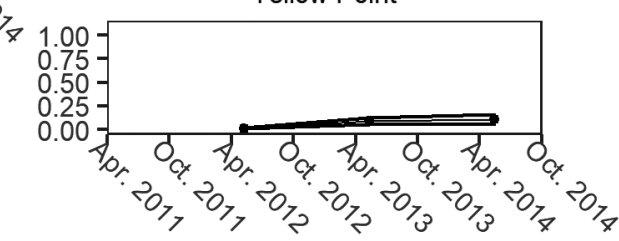

Date

Fig. 8. Proportion of Nucella lamellosa shells considered to be 'dead' (either empty or containing hermit crabs) at 11 field sites, categorized by 'low' or 'high' salinity classification. Points connected by lines indicated average percentage across transects; upper and lower limits to the shaded ribbons indicate SEM

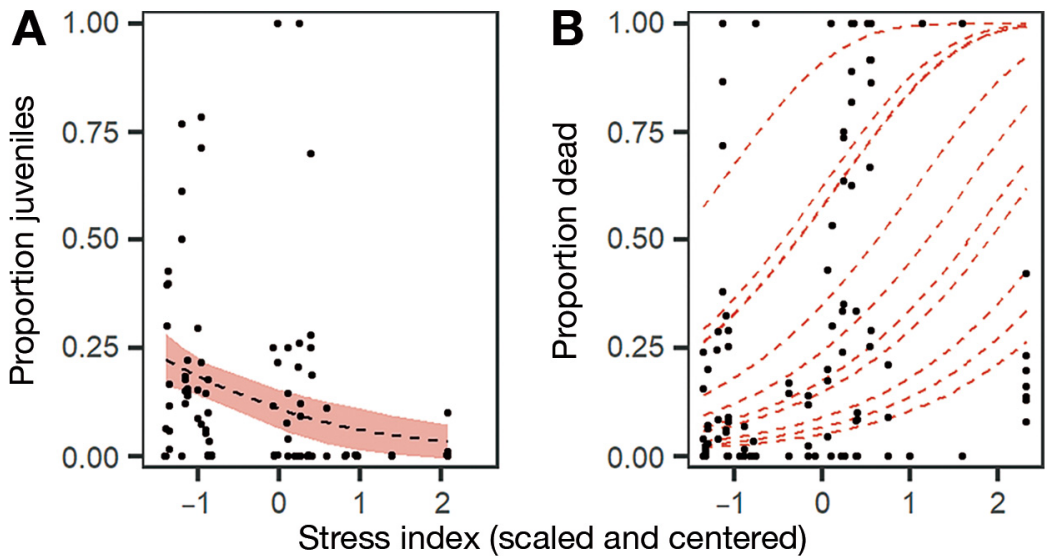

Fig. 9. Negative binomial generalized linear mixed-effects model (GLMM) predictions for (A) the relationship between the proportion of juveniles in a given transect, at a site, in a year, and salinity stress index from the previous year, and (B) the model relating the proportion of Nucella lamellosa shells that were dead (empty or containing hermit crabs) to salinity stress index, from the previous year. Actual data are plotted as points (jittered to increase visibility); model predictions are plotted as dashed lines, with $95 \%$ confidence interval indicated by the ribbon in (A). Model predictions are plotted across sites for (A), and within sites in (B), according to best fitting model structure that was used. Mean and SD for all values were used to scale and center the salinity stress index

33 psu water and left them for an additional $33 \mathrm{~d}$ (110 d since the initiation of the experiment), $25 \%$ of the egg capsules originally held at 20 psu had hatched, along with a single egg capsule previously held at $15 \mathrm{psu}$. Inspection under a dissecting microscope indicated that unhatched embryos previously held at 20 psu were continuing to develop but that unhatched embryos that had been exposed to lower salinities were all dead.

\subsection{Juveniles, adults, and salinity stress}

Following the exposure of juvenile and adult $N$. lamellosa to different salinity conditions, survivorship curves showed clear differences between age and treatment groups (Fig. 11). We only observed 1 death in the 20 psu salinity treatment: a White Rock adult individual. In the 9 psu salinity treatment $100 \%$ mortality occurred for White Rock juveniles after $8 \mathrm{~d}$, for White Rock adults after $14 \mathrm{~d}$, and for Tower Beach South adults after 17 d (Fig. 11). In the variable salinity treatment $64 \%$ of White Rock juveniles, $56 \%$ of White Rock adults, and $35 \%$ of 

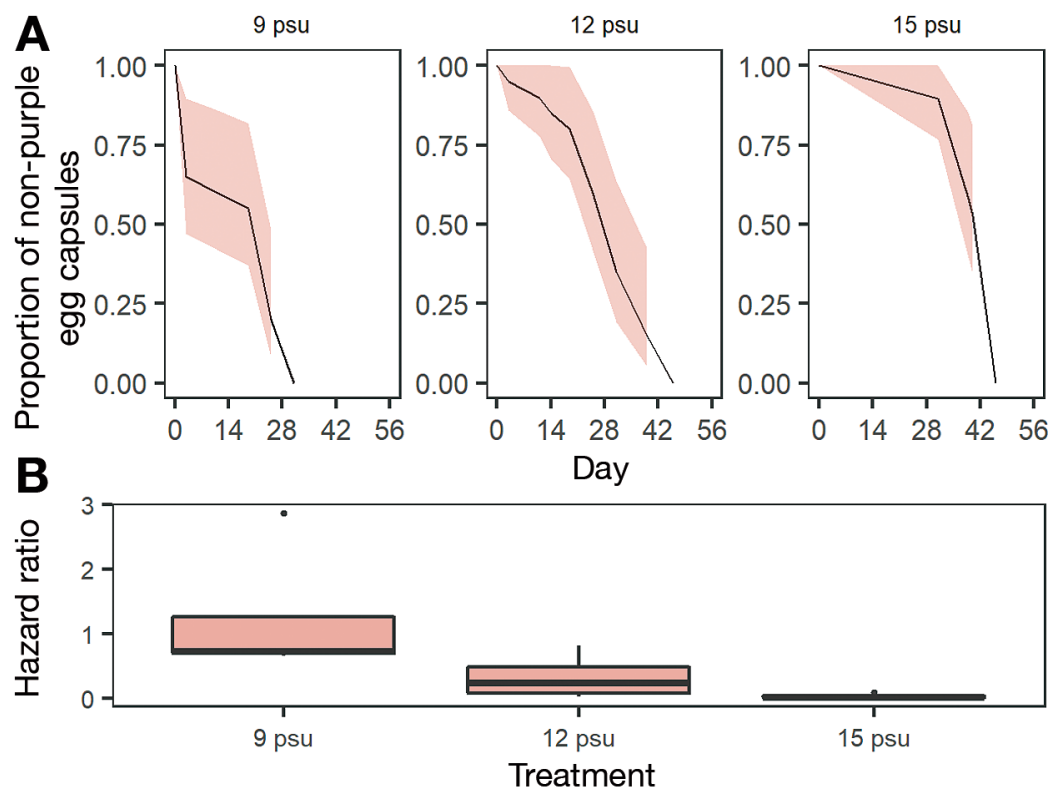

Fig. 10. (A) Kaplan-Meier survival curves, with $95 \%$ CI as ribbons, estimating time until stress event in encapsulated embryos of Nucella lamellosa held at 9, 12, and 15 psu during a 77 d experiment. (B) Hazard ratios for each of the 3 treatments, as predicted by mixed-effects Cox Proportional Hazards model. Purple colouration of embryos in egg capsules was used as a sign of stress, indicating a high likelihood of mortality. Embryos held at 20 and 25 psu did not consistently develop purple colouration over the course of the experiment, and are not plotted here
Tower Beach South adults had died by Day 21. According to the mixedeffects $\mathrm{CPH}$ model, population/age class, treatment, and shell length were all significant predictors of hazard of death $(\mathrm{p}=0.009, \mathrm{p}<0.001, \mathrm{p}<0.001$, respectively). Plotting the model predictions (Fig. 11) indicates that while hazard ratios decreased with increasing body size, the predicted difference in daily hazard ratios between 9 psu and variable salinity treatments were relatively low for adults, but higher for juveniles, with a roughly $40 \%$ increase in hazard for the smallest of juveniles (around $10 \mathrm{~mm}$ in length), held at constant low salinity, compared to all other sizes and treatments. All individuals were able to tolerate at least several days of 9 psu salinity stress, which likely produced the small differences in daily hazard ratios, which still compounded and caused significant differences in mortality over the course of the 3 wk experiment.
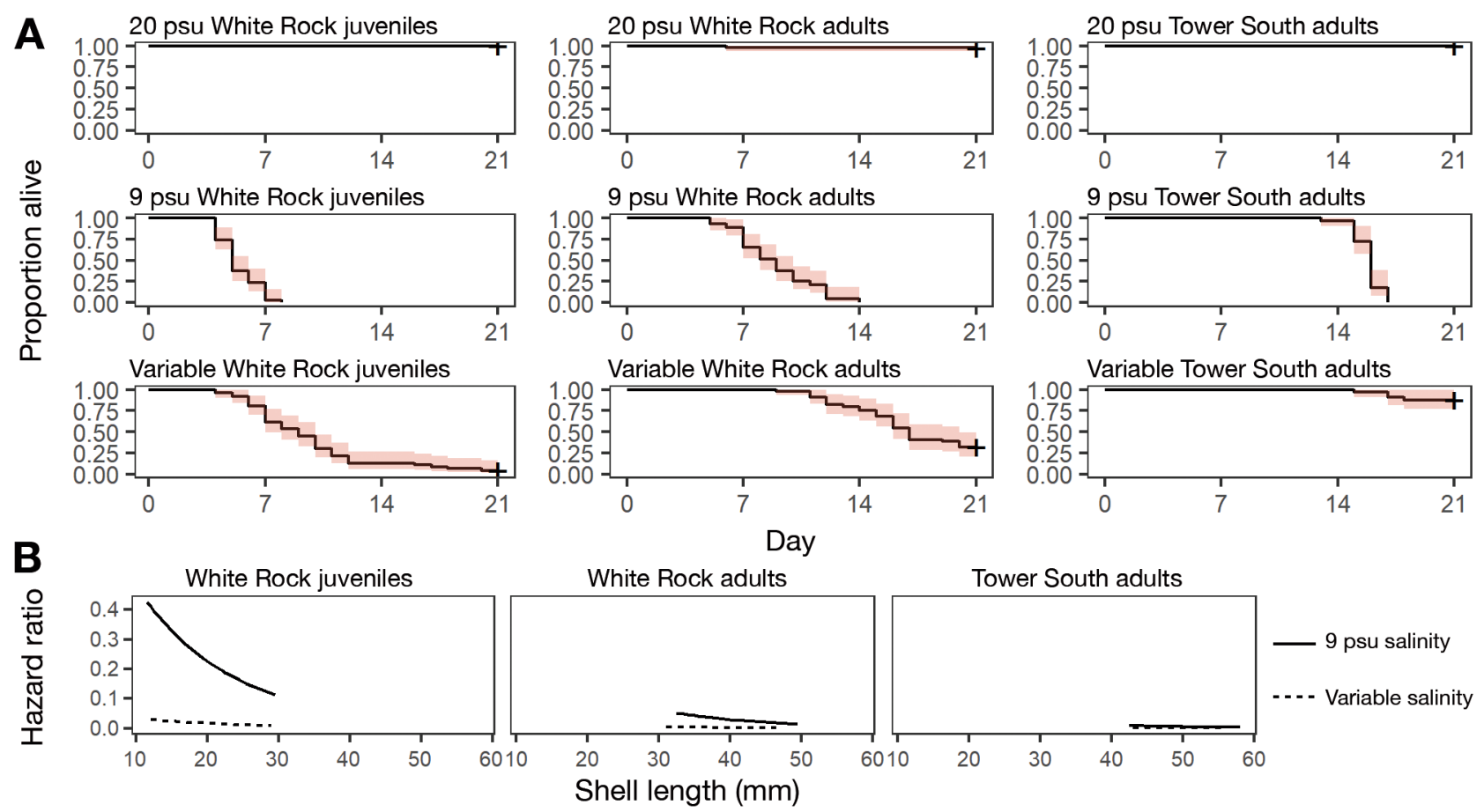

Fig. 11. (A) Kaplan-Meier survival curves estimating time until death for Nucella lamellosa adults and juveniles from 2 sites (White Rock and Tower Beach South ) exposed for 21 d to 3 salinity treatments: 20, 9, and 9 psu with daily 3 h 20 psu (variable). Ribbons indicate $95 \%$ confidence intervals. (B) Hazard ratio for each of the treatment and age/population classes in relation to body size (shell length), as predicted by a mixed-effects Cox Proportion Hazards model 
The LMM comparing salinity tolerance among individuals within the 9 psu salinity treatment determined that shell length $(\mathrm{p}<0.001)$, population $(\mathrm{p}<$ $0.01)$, and the interaction between the two $(p=0.01)$ were all significant predictors of day of death. The slope of the interaction term suggests that for each increase in shell length by $1 \mathrm{SD}$, White Rock individuals lost about 1.4 more days of survival than those from Tower Beach South. Put another way, the average-sized snail in the study $(34 \mathrm{~mm})$ could be expected to survive about 1.8 times as long if it were from Tower Beach South as opposed to White Rock, while an average plus $1 \mathrm{SD}$ snail $(47 \mathrm{~mm}$ ) could be expected to survive about 1.5 times as long.

\section{DISCUSSION}

The mechanistic links between the abiotic environment and the performance of individuals, the dynamics of populations, and the distribution of species have been an important area of ecological research for well over a century (e.g. Darwin 1859, Dunson \& Travis 1991, Harley et al. 2006, Sexton et al. 2009). The importance of environmental variation, especially through time, is now receiving increased scrutiny as the Earth's climate system is changing in rapid and complex ways. While earlier work tended to focus on mean conditions (Helmuth et al. 2014), there is an increasing appreciation of the importance of environmental variation, including the range of conditions likely to be encountered, the rate of change, history of the system, and the return time of extreme events (Denny et al. 2004, Dowd et al. 2015, Ryo et al. 2018). Further, the driving force of environmental change will operate differently on different populations within a species, different individuals within a population, and different ontogenetic stages within an individual (Linhart \& Grant 1996, Sinclair et al. 2016, Dong et al. 2017). Although the resolution and extent of ecological sampling often fails to match the scales of relevant processes (Estes et al. 2018), understanding the importance of environmental change at a variety of scales in time, space, and biological organization is a priority for the field of ecology. Here, we address the importance of variation in a key driver of ecological dynamics in estuaries - salinity - as it varies across multiple temporal scales and impacts multiple populations and various ontogenetic stages. We will discuss the response of Nucella lamellosa to salinity from the scale of the individual to that of the population, and from the scale of a single day to the scale of the next century of a changing climate.
At the individual level, N. lamellosa demonstrated some degree of variability in salinity tolerance, with patterns relating to ontogeny and population emerging. Juveniles were the least tolerant of extended periods of low salinity stress, with $100 \%$ mortality after an $8 \mathrm{~d}$ exposure to 9 psu. Adults were more tolerant, with $100 \%$ mortality reached after 14 to $17 \mathrm{~d}$ depending on site of collection. Encapsulated embryos appeared to be the most tolerant, and, on average, were able to withstand more than $2 \mathrm{wk}$ of exposure to $9 \mathrm{psu}$ without showing signs of stress (although they could not complete development at this salinity). Several factors could explain the difference between juveniles and adults, including greater metabolic rate in juveniles (Spight et al. 1974) and thus greater accumulation of harmful metabolic waste products and/or running out of oxygen while closed off from the environment. $N$. lapillus of shell length comparable to the juveniles used in our study similarly suffered complete mortality after $5 \mathrm{~d}$ at 11 psu (Leung et al. 2002). Adults may also be better able to depress their metabolism and/or switch to anaerobic respiration and thus be better able to survive long periods closed off from the environment (Sokolova et al. 2011). Notably, salinity tolerance increased linearly with body size for all $N$. lamellosa individuals, suggesting the effect may be related to factors beyond sexual maturity. Our experimental design could not distinguish acclimatization from local adaptation as accounting for the higher tolerance in Tower Beach South snails, but our results relating body size and site to salinity tolerance support the idea that individuals from this site are both more tolerant as they get larger and also more tolerant at a specific size than snails from White Rock. The population model also indicates a shallower slope for the relationship between salinity and population size at Tower Beach South than at other sites, which supports the idea of local acclimatization or adaptation. Acclimation/acclimatization to salinity stress by $N$. lamellosa has previously been demonstrated in the lab and field (Johannsson 1971) with little evidence for local adaptation. The snails from Tower Beach South produced large amounts of mucus during our experiment, in comparison with the White Rock snails, which is a mechanism by which the body tissue can be physically separate from the hypoosmotic seawater (Grimm-Jørgensen et al. 1986) and one of the pathways by which such acclimation or adaptation could occur. If size is protective, there may also be incentive for juvenile snails at high salinity sites to get large rapidly. $N$. lamellosa display a large degree of phenotypic plasticity (Bourdeau 2012), and 
increased growth rates could happen in response to a number of factors that occur closer to the mouth of the Fraser River, including higher temperatures (Sanford 2002) and reduced predation from salinitysensitive predators like Pisaster ochraceus (Held \& Harley 2009).

All size-classes of $N$. lamellosa displayed a strong reduction in mortality when exposed to variable salinity simulating tidal fluctuations in a stratified water column. Thus, during periods of high Fraser River outflow, for individuals that would otherwise be living at or beyond their long-term limits in salinity tolerance, the right combination of low salinity layer depth and tidal cycle timing will allow for a daily respite from low salinity stress and allow for extended survival during low salinity events. Gastropods close their operculum to shut themselves off from the environment and maintain a hyperosmotic state in their perivisceral fluids and blood to allow for gradual acclimation when exposed to a sudden drop in salinity (Hoyaux et al. 1976). The N. lamellosa in this study were likely unable to acclimate to 9 psu to a point where they could respire normally while exposed to the environment (Berger \& Kharazova 1997). Those given the variable salinity treatment, however, would sometimes emerge and reattach to the walls of their containers following the daily $3 \mathrm{~h}$ high salinity exposure. N. lamellosa is unable to regulate its intracellular volume by altering its amino acid concentrations, compared to other muricids (Kapper et al. 1985, Stickle et al. 1985), and daily exposure to high salinity may allow it to recover its cellular volume and thus be better prepared to survive the next low salinity exposure. Stickle et al. (1985) demonstrated that a semidiurnal pattern of changing salinity between 30 and 17.5 psu reduced the feeding activity of $N$. lapillus individuals that were acclimated to $30 \mathrm{psu}$, but not as much as in individuals held at a constant 17.5 psu. Relief during high tide could thus decrease fitness costs even during low salinity events of lesser magnitude than the one implemented in our study, although all non-embryonic N. lamellosa in our study appeared to be well adapted to function at 20 psu. Interestingly, adults showed a greater reduction in mortality rate relative to juveniles in the variable salinity treatment compared to the low salinity treatment, suggesting the possibility that adults are better able to take advantage of brief periods of raised salinity to recover from low salinity stress and prepare for the next exposure. It can also not be ruled out that individuals in the field may be able move to lower tidal levels and thus escape the low salinity layer (Lambert \& Dehnel
1974). This may be more advantageous for adults, which can better survive the higher predation pressure of the subtidal. Habitat structure is also likely to limit the ability to disperse, as N. lamellosa populations living on rocky outcroppings embedded in sandy beaches (such as at Tower Beach North) might not be able to make the journey and could thus be driven to local extinction during years of extreme low salinity, as seen during our population surveys.

The size and structure of $N$. lamellosa populations, at the scale of the Fraser River estuary, were dependent on both inter- and intra-annual variability in the outflow of the Fraser River. Extended periods of low salinity caused higher mortality rates, as evidenced in the laboratory experiments, with $4 \mathrm{~d}$ prior Fraser River outflow an excellent predictor of salinity at the Burrard Inlet sites. Extrapolating the salinity model to create a measure of annual salinity stress and correlating with the results from $N$. lamellosa population surveys demonstrated that at low salinity sites, population density during the spring was strongly dependent on salinity during the previous year. In the year following a year of high spring/summer Fraser River outflow, populations of $N$. lamellosa living near the mouth of the Fraser River suffered decreases in population size and near complete loss of young-ofthe-year juveniles. Developmental delay and increased mortality in encapsulated embryos that had not hatched before the spring freshet likely exacerbated the loss of juveniles, in addition to high mortality for recently hatched juveniles. However, encapsulated embryos have the potential to out-survive young-of-the-year, and provide a source of juveniles to the population in the following year, if salinity stress is not too prolonged or severe. Thus, the key environmental factors that will influence the persistence and age-class structure of $N$. lamellosa populations are the magnitude of low salinity experienced, the duration of exposure, and the presence of a period of relief during high tide, which depend in turn upon the duration and magnitude of Fraser River outflow during the freshet, the degree of vertical mixing, and the depth of the freshwater lens. Other environmental factors such as precipitation and other freshwater inputs may play some smaller role, as well as the depth of the low salinity layer generated by the freshet and its interactions with the coexisting tidal flux. For sites that were further away from the mouth of the Fraser River, or protected from its influence by geographical and/or topographic barriers, salinity did not appear to play a role in structuring populations and interannual variation in population size and structure were likely driven by other 
factors, such as predation, competition, and prey availability.

If a $N$. lamellosa population can survive withinyear variability in salinity and persist through an especially large freshet, its continued persistence will then be dependent on inter-annual variability in Fraser River outflow and its influence on local salinity. If only a single high-salinity year follows a lowsalinity year before a return to extreme salinity lows, juveniles may not be able to make it to maturity and will not be able to replenish the population, but some encapsulated embryos might survive to produce a young-of-the-year group for the following year. Larger adults may be able to survive a run of several consecutive low-salinity years but will eventually die from salinity stress or other causes of mortality. For a population to persist, a high salinity year must occur before enough consecutive low salinity years have occurred to have wiped out the breeding population of adults. Climate change and increasing temperatures will decrease snowpack and shift snowmelt and peak outflow of the Fraser River to earlier in the year, increasing the inter-year variability of the annual peak outflow while decreasing its average volume. Predictions suggest a gradual shift from a snowmelt to a precipitation dominated runoff regime, with increased average outflow during the winter, and decreased average outflow in the summer following peak outflow in the spring (Morrison et al. 2002, Shrestha et al. 2012). The peak of the freshet is also predicted to be lower and occur earlier in the year (Morrison et al. 2002), suggesting that the seasonal drop in coastal salinity in the southern Strait of Georgia will occur earlier in the year over time, and will become more limited in magnitude. This may benefit $N$. lamellosa populations in the Fraser estuary and reduce the strength of the dependency with salinity of these populations' size and structure. However, increased inter-annual variability in freshwater runoff in the Fraser River Basin (Déry et al. 2012) may increase the stochasticity of low salinity events. This could reduce the probability of a run of good years occurring and make it more difficult for the N. lamellosa populations in the estuary to persist. What might be most likely is for reduction or extirpation of the populations living closest to the mouth of the Fraser River to occur, while populations located farther away shift to a less salinity-dominated regime.

Climate change and changes in the dynamics of Fraser River runoff may have already influenced the distribution of $N$. lamellosa populations. Data collected in 1970 (Johannsson 1971) suggests that $N$. lamellosa population were not present at either of the
Tower Beach sites surveyed in our study. The persistence of a population at Tower Beach South during our study, despite many years of very low salinity, suggests that the movement of the species into this area may have been facilitated by changes in the outflow of the Fraser River over the prior 4 decades. Projecting our salinity model from 1986-2016 for Tower Beach South suggests that while not significant according to linear models, there is a trend for the number of days in a year where the local salinity drops below 9 psu to be increasing time (see Fig. S3 in the Supplement) while other factors, including the number of days when salinity dropped below 15 psu, annual mean salinity, and annual salinity variance are trending downwards. This further emphasizes that variation in salinity cannot be considered at a single scale to make population and/or species level predictions. The overall increase in days in a year where the salinity drops below 9 psu, over the last 4 decades, would be thought to be limiting the spread of $N$. lamellosa into the area. However, other factors, such as increasing interannual variability in low salinity, have facilitated the establishment of an $N$. lamellosa population at this site. Despite more stressful years occurring, there have clearly still been enough low stress years between these high stress years to allow the population to persist.

The shift of the Fraser River freshet to earlier in the year may also increase overlap with the timing of hatching N. lamellosa juveniles in the spring, and prevent juveniles from reaching a sufficient size to survive even brief low salinity events. $N$. lamellosa egg capsules, still unhatched in the early spring, can be quite sensitive to lengthy periods of low salinity exposure (Stickle \& Denoux 1976). In fact, N. lamellosa living near Vancouver appear to lay their eggs earlier in the year than conspecifics on the central coast of British Columbia (F. Beaty pers. comm.), suggesting the possibility of a phenological adaptation allowing egg capsules to hatch, and/or juveniles to reach a certain size before the peak of the Fraser River outflow occurs. Hatching out juveniles earlier in the year may also be beneficial for $N$. lamellosa populations living near the Burrard inlet, as juveniles could at least move lower in the intertidal zone to some extent compared with stationary egg capsules.

At low salinity sites, population growth rates were determined by the duration and magnitude of salinity extremes during prior years. One of the primary mechanisms by which low salinity events influence population growth may be by limiting the survival and delaying the development of encapsulated embryos, and by causing the mortality of young-of- 
the-year juveniles. Alternatively, the presence of large variation in population size at high salinity sites suggests that other stochastic forces are still at play, for example, resource provisioning, competition and/or predation. On the scale of the entire Fraser estuary, N. lamellosa populations may benefit from the predicted decrease in magnitude of low salinity events under a changing climate. The increased abundance in the Fraser estuary of such a voracious predator may have important consequences for intertidal and subtidal ecosystems. However, the earlier onset of peak river outflow and a precipitation dominated runoff regime may negatively affect $N$. lamellosa near the mouth of the Fraser River by exposing sensitive age and size classes to earlier or longer periods of moderately decreased salinity, although increased year-to-year variability may allow populations to persist by offering enough years of low salinity during which they can recover. Our work advances the understanding of how abiotic factors can operate across spatiotemporal scales to drive population dynamics and demonstrates how ecologists might miss important interactions if they consider interactions between organisms and their environment at only a single scale.

Acknowledgements. We acknowledge that this research was carried out on the traditional, ancestral, and unceded territory of the Coast Salish Peoples. We thank O. Johannsson for thoughtful discussion and A. Lambert for assistance in the field. This work was supported by a Natural Sciences and Engineering Research Council (NSERC) Discovery Grant to C.D.G.H. and a NSERC Undergraduate Student Research Award to G.A.C.

\section{LITERATURE CITED}

Agüera A, Schellekens T, Jansen JM, Smaal AC (2015) Effects of osmotic stress on predation behaviour of Asterias rubens L. J Sea Res 99:9-16

Baird PH (1990) Influence of abiotic factors and prey distribution on diet and reproductive success of three seabird species in Alaska. Ornis Scand 21:224-235

Barletta M, Barletta-Bergan A, Saint-Paul U, Hubold G (2005) The role of salinity in structuring the fish assemblages in a tropical estuary. J Fish Biol 66:45-72

Barton K (2018) MuMIn: multi-model inference. https:// CRAN.R-project.org/package=MuMIn

* Bennett WA, Kimmerer WJ, Burau JR (2002) Plasticity in vertical migration by native and exotic estuarine fishes in a dynamic low-salinity zone. Limnol Oceanogr 47: 1496-1507

Berger VJ, Kharazova AD (1997) Mechanisms of salinity adaptations in marine molluscs. Hydrobiologia 355:115-126

Botero CA, Weissing FJ, Wright J, Rubenstein DR (2015) Evolutionary tipping points in the capacity to adapt to environmental change. Proc Natl Acad Sci USA 112: $184-189$
Bourdeau PE (2012) Intraspecific trait cospecialization of constitutive and inducible morphological defences in a marine snail from habitats with different predation risk: trait cospecialization in a marine snail. J Anim Ecol 81:849-858

Boyce MS, Haridas CV, Lee CT, NCEAS Stochastic Demography Working Group (2006) Demography in an increasingly variable world. Trends Ecol Evol 21:141-148

Brooks ME, Kristensen K, van Benthem KJ, Magnusson A and others (2017) GlmmTMB balances speed and flexibility among packages for zero-inflated generalized linear mixed modeling. R J 9:378-400

Chan WP, Chen IC, Colwell RK, Liu WC, Huang C, Shen SF (2016) Seasonal and daily climate variation have opposite effects on species elevational range size. Science 351:1437-1439

Chapman PM, Brinkhurst RO (1981) Seasonal changes in interstitial salinities and seasonal movements of subtidal benthic invertebrates in the Fraser River estuary, B.C. Estuar Coast Shelf Sci 12:49-66

C Cloern JE, Abreu PC, Carstensen J, Chauvaud L and others (2016) Human activities and climate variability drive fast-paced change across the world's estuarine-coastal ecosystems. Glob Change Biol 22:513-529

* Coma R, Ribes M, Serrano E, Jiménez E, Salat J, Pascual J (2009) Global warming-enhanced stratification and mass mortality events in the Mediterranean. Proc Natl Acad Sci USA 106:6176-6181

Connell JH (1970) A predator-prey system in the marine intertidal region. I. Balanus glandula and several predatory species of Thais. Ecol Monogr 40:49-78

Darwin C (1859) On the origin of species, $6^{\text {th }}$ edn. D. Appleton and Company, New York, NY

* Deegan LA (1990) Effects of estuarine environmental conditions on population dynamics of young-of-the-year gulf menhaden. Mar Ecol Prog Ser 68:195-205

* Denny MW, Helmuth B, Leonard GH, Harley CDG, Hunt LJH, Nelson EK (2004) Quantifying scale in ecology: lessons from a wave-swept shore. Ecol Monogr 74:513-532

* Déry SJ, Hernández-Henríquez MA, Owens PN, Parkes MW, Petticrew EL (2012) A century of hydrological variability and trends in the Fraser River Basin. Environ Res Lett 7:024019

* Dolbeth M, Cardoso PG, Grilo TF, Bordalo MD, Raffaelli D, Pardal MA (2011) Long-term changes in the production by estuarine macrobenthos affected by multiple stressors. Estuar Coast Shelf Sci 92:10-18

* Dong YW, Li X, Choi FMP, Williams GA, Somero GN, Helmuth B (2017) Untangling the roles of microclimate, behaviour and physiological polymorphism in governing vulnerability of intertidal snails to heat stress. Proc Biol Sci 284:20162367

Douglass JG, Chamberlain RH, Wan Y, Doering PH (2020) Submerged vegetation responses to climate variation and altered hydrology in a subtropical estuary: interpreting 33 years of change. Estuar Coast, https://doi.org/10. 1007/s12237-020-00721-4

Nowd WW, King FA, Denny MW (2015) Thermal variation, thermal extremes and the physiological performance of individuals. J Exp Biol 218:1956-1967

* Drouin G, Himmelman JH, Béland P (1985) Impact of tidal salinity fluctuations on echinoderm and mollusc populations. Can J Zool 63:1377-1387

* Dunson WA, Travis J (1991) The role of abiotic factors in community organization. Am Nat 138:1067-1091

*Easterling DR, Meehl GA, Parmesan C, Changnon SA, Karl TR, Mearns LO (2000) Climate extremes: observations, modeling, and impacts. Science 289:2068-2074 
Ernest SKM, Brown JH, Parmenter RR (2000) Rodents, plants, and precipitation: spatial and temporal dynamics of consumers and resources. Oikos 88:470-482

Estes L, Elsen PR, Treuer T, Ahmed L and others (2018) The spatial and temporal domains of modern ecology. Nat Ecol Evol 2:819-826

Firth LB, Knights AM, Bell SS (2011) Air temperature and winter mortality: implications for the persistence of the invasive mussel, Perna viridis in the intertidal zone of the south-eastern United States. J Exp Mar Biol Ecol 400: $250-256$

Garrabou J, Coma R, Bensoussan N, Bally M and others (2009) Mass mortality in northwestern Mediterranean rocky benthic communities: effects of the 2003 heat wave. Glob Change Biol 15:1090-1103

Gibson RN, Pihl L, Burrows MT, Modin J, Wennhage H, Nickell LA (1998) Diel movements of juvenile plaice Pleuronectes platessa in relation to predators, competitors, food availability and abiotic factors on a microtidal nursery ground. Mar Ecol Prog Ser 165:145-159

Gosselin LA, Qian PY (1997) Juvenile mortality in benthic marine invertebrates. Mar Ecol Prog Ser 146:265-282

Government of Canada (2019) Water level and flow. https:// wateroffice.ec.gc.ca/index_e.html (accessed May 22, 2019)

Grimm-Jørgensen Y, Ducor ME, Piscatelli J (1986) Surface mucus production in gastropods is dependent on environmental salinity and humidity. Comp Biochem Physiol A Physiol 83:415-419

Halverson MJ, Pawlowicz R (2008) Estuarine forcing of a river plume by river flow and tides. J Geophys Res Oceans 113:C09033

Harley CDG, Hughes AR, Hultgren KM, Miner BG and others (2006) The impacts of climate change in coastal marine systems. Ecol Lett 9:228-241

Held MBE, Harley CDG (2009) Responses to low salinity by the sea star Pisaster ochraceus from high- and low-salinity populations. Invertebr Biol 128:381-390

Helmuth B, Russell BD, Connell SD, Dong Y and others (2014) Beyond long-term averages: making biological sense of a rapidly changing world. Clim Change Responses 1:6

Horiguchi T, Li Z, Uno S, Shimizu M and others (2004) Contamination of organotin compounds and imposex in molluscs from Vancouver, Canada. Mar Environ Res 57: 75-88

Hoyaux J, Gilles R, Jeuniaux Ch (1976) Osmoregulation in molluscs of the intertidal zone. Comp Biochem Physiol A Physiol 53:361-365

IPCC (Intergovernmental Panel on Climate Change) (2014) Climate change 2013: The physical science basis: Working Group I contribution to the Fifth Assessment Report of the Intergovernmental Panel on Climate Change. Cambridge University Press, Cambridge

Jackson ST, Hobbs RJ (2009) Ecological restoration in the light of ecological history. Science 325:567-569

Johannsson OE (1971) Effect of reduced salinity conditions on the distribution and responses of the muricid intertidal snail Thais lamellosa Gmelin. MSc Thesis, University of British Columbia, Vancouver, BC

Kaplan EL, Meier P (1958) Nonparametric estimation from incomplete observations. J Am Stat Assoc 53:457-481

Kapper MA, Stickle WB, Blakeney E (1985) Volume regulation and nitrogen metabolism in the muricid gastropod Thais haemastoma. Biol Bull 169:458-475

Kay SWC, Gehman ALM, Harley CDG (2019) Reciprocal abundance shifts of the intertidal sea stars, Evasterias troschelii and Pisaster ochraceus, following sea star wasting disease. Proc Biol Sci 286:20182766

Kuo ESL, Sanford E (2009) Geographic variation in the upper thermal limits of an intertidal snail: implications for climate envelope models. Mar Ecol Prog Ser 388: 137-146

Lambert P, Dehnel PA (1974) Seasonal variations in biochemical composition during the reproductive cycle of the intertidal gastropod Thais lamellosa Gmelin (Gastropoda, Prosobranchia). Can J Zool 52:305-318

* Laptikhovsky V, Barrett C, Firmin C, Hollyman P and others (2016) A novel approach for estimation of the natural mortality of the common whelk, Buccinum undatum (L.) and role of hermit crabs in its shell turnover. Fish Res 183:146-154

L Lawson CR, Vindenes Y, Bailey L, van de Pol M (2015) Environmental variation and population responses to global change. Ecol Lett 18:724-736

*Leonard GH (2000) Latitudinal variation in species interactions: a test in the New England rocky intertidal zone. Ecology 81:1015-1030

Lepori F, Hjerdt N (2006) Disturbance and aquatic biodiversity: reconciling contrasting views. Bioscience 56:809-818

* Leung KMY, Svavarsson J, Crane M, Morritt D (2002) Influence of static and fluctuating salinity on cadmium uptake and metallothionein expression by the dogwhelk Nucella lapillus (L.). J Exp Mar Biol Ecol 274:175-189

K Levin SA (1992) The problem of pattern and scale in ecology: the Robert H. MacArthur Award lecture. Ecology 73:1943-1967

* Linhart YB, Grant MC (1996) Evolutionary significance of local genetic differentiation in plants. Annu Rev Ecol Syst 27:237-277

KLougee LA, Bollens SM, Avent SR (2002) The effects of haloclines on the vertical distribution and migration of zooplankton. J Exp Mar Biol Ecol 278:111-134

Miller LP, Harley CDG, Denny MW (2009) The role of temperature and desiccation stress in limiting the local-scale distribution of the owl limpet, Lottia gigantea. Funct Ecol 23:756-767

Miron GY, Desrosiers GL (1990) Distributions and population structures of two intertidal estuarine polychaetes in the lower St. Lawrence Estuary, with special reference to environmental factors. Mar Biol 105:297-306

*Moreno J, Møller AP (2011) Extreme climatic events in relation to global change and their impact on life histories. Curr Zool 57:375-389

* Morrison J, Quick MC, Foreman MG (2002) Climate change in the Fraser River watershed: flow and temperature projections. J Hydrol (Amst) 263:230-244

Muenchow G (1986) Ecological use of failure time analysis. Ecology 67:246-250

* Nasrolahi A, Havenhand J, Wrange AL, Pansch C (2016) Population and life-stage specific sensitivities to temperature and salinity stress in barnacles. Sci Rep 6:32263

* Ong JJL, Nicholas Rountrey A, Jane Meeuwig J, John Newman S, Zinke J, Gregory Meekan M (2015) Contrasting environmental drivers of adult and juvenile growth in a marine fish: implications for the effects of climate change. Sci Rep 5:10859

Pearson GA, Lago-Leston A, Mota C (2009) Frayed at the edges: selective pressure and adaptive response to abiotic stressors are mismatched in low diversity edge populations. J Ecol 97:450-462

* Pechenik JA (1982) Ability of some gastropod egg capsules to protect against low-salinity stress. J Exp Mar Biol Ecol 63:195-208 
Pérez-Castañeda R, Defeo O (2004) Spatial distribution and structure along ecological gradients: penaeid shrimps in a tropical estuarine habitat of Mexico. Mar Ecol Prog Ser 273:173-185

Pinheiro J, Bates D, DebRoy S, Sarkar D, R Core Team (2018) nlme: linear and nonlinear mixed effects models. https://CRAN.R-project.org/package=nlme

R Core Team (2019) R: a language and environment for statistical computing. R Foundation for Statistical Computing, Vienna

Reed TE, Waples RS, Schindler DE, Hard JJ, Kinnison MT (2010) Phenotypic plasticity and population viability: the importance of environmental predictability. Proc Biol Sci 277:3391-3400

Riche O, Johannessen SC, Macdonald RW (2014) Why timing matters in a coastal sea: trends, variability and tipping points in the Strait of Georgia, Canada. J Mar Syst 131:36-53

Ryo M, Yoshimura C, Iwasaki Y (2018) Importance of antecedent environmental conditions in modeling species distributions. Ecography 41:825-836

Ryo M, Aguilar-Trigueros CA, Pinek L, Muller LAH, Rillig MC (2019) Basic principles of temporal dynamics. Trends Ecol Evol 34:723-733

Sanford E (2002) The feeding, growth, and energetics of two rocky intertidal predators (Pisaster ochraceus and Nucella canaliculata) under water temperatures simulating episodic upwelling. J Exp Mar Biol Ecol 273:199-218

Sexton JP, McIntyre PJ, Angert AL, Rice KJ (2009) Evolution and ecology of species range limits. Annu Rev Ecol Evol Syst 40:415-436

Shrestha RR, Schnorbus MA, Werner AT, Berland AJ (2012) Modelling spatial and temporal variability of hydrologic impacts of climate change in the Fraser River basin, British Columbia, Canada. Hydrol Processes 26: 1840-1860

Shumway SE (1979) The effects of fluctuating salinity on respiration in gastropod molluscs. Comp Biochem Physiol A Physiol 63:279-283

Sinclair BJ, Marshall KE, Sewell MA, Levesque DL and others (2016) Can we predict ectotherm responses to climate change using thermal performance curves and body temperatures? Ecol Lett 19:1372-1385

Sokolova IM, Sukhotin AA, Lannig G (2011) Stress effects on metabolism and energy budgets in mollusks. In: Abele D, Vázquez-Medina JP, Zenteno-Savín T (eds) Oxidative stress in aquatic ecosystems. Wiley-Blackwell, Hoboken, NJ, p 261-280

Soontiens N, Allen SE, Latornell D, Souëf KL and others (2016) Storm surges in the Strait of Georgia simulated with a regional model. Atmos-ocean 54:1-21

Sorte CJB, Fuller A, Bracken MES (2010) Impacts of a simulated heat wave on composition of a marine community. Oikos 119:1909-1918

Sousa WP (1979) Disturbance in marine intertidal boulder fields: the nonequilibrium maintenance of species diversity. Ecology 60:1225-1239

Spight TM (1974) Sizes of populations of a marine snail. Ecology 55:712-729

Spight TM (1975) Factors extending gastropod embryonic development and their selective cost. Oecologia 21:1-16

Spight TM (1981) How three rocky shore snails coexist on a limited food resource. Res Popul Ecol (Kyoto) 23:245-261

Spight TM, Birkeland C, Lyons A (1974) Life histories of large and small murexes (Prosobranchia: Muricidae). Mar Biol 24:229-242
Stickle WB, Denoux GJ (1976) Effects of in situ tidal salinity fluctuations on osmotic and ionic composition of body fluid in southeastern Alaska Rocky intertidal fauna. Mar Biol 37:125-135

Stickle WB, Moore MN, Bayne BL (1985) Effects of temperature, salinity and aerial exposure on predation and lysosomal stability of the dogwhelk Thais (Nucella) lapillus (L.). J Exp Mar Biol Ecol 93:235-258

* Therneau TM (2015) A package for survival analysis in S. https://CRAN.R-project.org/package=survival

Therneau TM (2019) Coxme: mixed effects Cox models. https://CRAN.R-project.org/package=coxme

Therneau TM, Grambsch PM (2015) Modeling survival data: extending the Cox model. Springer, New York, NY

Thompson JAJ, Reitsema TJ, Wilson RCH (2005) An overview of recent organotin studies in the Georgia Basin. In: Proceedings of the 2005 Puget Sound Georgia Basin Research Conference. http://citeseerx.ist.psu.edu/ viewdoc/summary?doi=10.1.1.669.6674

Tielbörger K, Kadmon R (2000) Temporal environmental variation tips the balance between facilitation and interference in desert plants. Ecology 81:1544-1553

Tolley SG, Volety AK, Savarese M (2005) Influence of salinity on the habitat use of oyster reefs in three southwest Florida estuaries. J Shellfish Res 24:127-137

Tonkin JD, Bogan MT, Bonada N, Rios-Touma B, Lytle DA (2017) Seasonality and predictability shape temporal species diversity. Ecology 98:1201-1216

Van Den Hoek C (1982) The distribution of benthic marine algae in relation to the temperature regulation of their life histories. Biol J Linn Soc 18:81-144

*Vázquez DP, Gianoli E, Morris WF, Bozinovic F (2017) Ecological and evolutionary impacts of changing climatic variability. Biol Rev Camb Philos Soc 92:22-42

*Vasseur DA, DeLong JP, Gilbert B, Greig HS and others (2014) Increased temperature variation poses a greater risk to species than climate warming. Proc Biol Sci 281: 20132612

V Verdelhos T, Marques JC, Anastácio P (2015) The impact of estuarine salinity changes on the bivalves Scrobicularia plana and Cerastoderma edule, illustrated by behavioral and mortality responses on a laboratory assay. Ecol Indic 52:96-104

*Ward PRB (1976) Seasonal salinity changes in the Fraser River Estuary. Can J Civ Eng 3:342-348

WWesterbom M, Kilpi M, Mustonen O (2002) Blue mussels, Mytilus edulis, at the edge of the range: population structure, growth and biomass along a salinity gradient in the north-eastern Baltic Sea. Mar Biol 140:991-999

Wiens JA (1986) Overview: the importance of spatial and temporal scale in ecological investigations. In: Case TJ, Diamond J (eds) Community ecology. Harper \& Row, New York, NY, p 145-153

*Winder M, Jassby AD, Nally RM (2011) Synergies between climate anomalies and hydrological modifications facilitate estuarine biotic invasions. Ecol Lett 14:749-757

Witman JD, Grange KR (1998) Links between rain, salinity, and predation in a rocky subtidal community. Ecology 79:2429-2447

*Wolkovich EM, Cook BI, McLauchlan KK, Davies TJ (2014) Temporal ecology in the Anthropocene. Ecol Lett 17: 1365-1379

Yamada SB (1989) Are direct developers more locally adapted than planktonic developers? Mar Biol 103:403-411

Zippay ML, Hofmann GE (2010) Physiological tolerances across latitudes: thermal sensitivity of larval marine snails (Nucella spp.). Mar Biol 157:707-714 